\title{
Analysis of Climate Variability Effects on Wheat Stem Rust (Puccinia graminis f.sp tritici) Epidemics in Bale and Arsi Zones of Oromia Regional State, Ethiopia
}

\author{
Tamene Mideksa ${ }^{1,}$, , Chemeda Fininsa ${ }^{2}$, Bekele Hundie ${ }^{3}$ \\ ${ }^{1}$ Oromia Agricultural Research Institute, Sinana Agricultural Research Center, Bale-Robe, Ethiopia \\ ${ }^{2}$ School of Plant Sciences, Haramaya University, Dire Dawa, Ethiopia \\ ${ }^{3}$ Ethiopian Agricultural Research Institute, Kulumsa Agricultural Research Center, Asella, Ethiopia \\ Email address: \\ gutamesa@gmail.com(T.Mideksa) \\ ${ }^{*}$ Corresponding author
}

\section{To cite this article:}

Tamene Mideksa, Chemeda Fininsa, Bekele Hundie. Analysis of Climate Variability Effects on Wheat Stem Rust (Puccinia graminis f.sp tritici) Epidemics in Bale and Arsi Zones of Oromia Regional State, Ethiopia. American Journal of Biological and Environmental Statistics. Vol. 4, No. 2, 2018, pp. 49-65. doi: 10.11648/j.ajbes.20180402.12

Received: February 15, 2018; Accepted: March 7, 2018; Published: March 30, 2018

\begin{abstract}
Stem rust caused by Puccinia graminis f.sp tritici, is the most destructive disease of wheat in the world. Bale and Arsi zones are conducive for stem rust epidemics. The study was conducted in 2013 to assess and model the effect of climate variability on wheat stem rust epidemics. The meteorological and disease data for the year 2004 to 2013 of Sinana and Kulumsa were obtained from the respective research centers and were analyzed. Four bread wheat cultivars, namely Kubsa, Madawalabu, Sofumer and Tusie were included in the study. The present study showed that stem rust epidemics was higher at kulumsa than at Sinana over the last 10 years. The increased stem rust severity at Sinana and Kulumsa were due to the total seasonal rainfall increase during wheat growing seasons. A reduction in stem rust severity was manifested at Sinana and kulumsa as seasonal mean minimum temperature increased, whereas a reduction in stem rust severity occurred at Kulumsa as the seasonal average relative humidity increased. The total seasonal rainfall had positive effect on the development of wheat stem rust, while the seasonal mean minimum temperature and seasonal average relative humidity significantly affected the development of wheat stem rust in the field.
\end{abstract}

Keywords: Climate Variability, Puccinia graminis f.sp. tritici, Stem Rust, Triticum aestivum, Wheat Cultivars

\section{Introduction}

Wheat (Triticum aestivum L.) is one of the most important crops in the world in production and nutrition. It is used mainly for human consumption and supports nearly $35 \%$ of the world population [11]. Wheat is one of the most important cereals cultivated in Ethiopia. The area under wheat production is estimated to be about 1.7 million hectares, which makes the country the largest wheat producer in Sub-Saharan Africa [15], [8]. The national average wheat productivity is low $2.54 \mathrm{t} / \mathrm{ha}$ [8]. Wheat is largely grown in the highlands of Ethiopia and constitutes $24.6 \%$ of the annual cereal production and plays an important role in supplying the population with various nutritional advantages [7]. It is grown at an altitudinal ranging from 1500 to 3000 m.a.s.1., between $6-16^{\circ} \mathrm{N}$ latitude and $35-42^{\circ} \mathrm{E}$ longitude in Ethiopia. The most suitable agro-ecological zones, however, fall between 1900 and 2700 m.a.s.l. [1]. Wheat production is severely affected by abiotic and biotic stresses [29]. Wheat rusts, notably stem and stripe rusts, have periodically caused damaging crop losses to Ethiopian wheat production. Stem rust, has been the most devastating of all wheat diseases under favorable conditions. It is favored by humid condition and relatively warm temperature under which it can cause great yield losses. Currently, the widespread use of resistant and early maturing cultivars worldwide has reduced the disease to a less significant level except in Eastern Africa where it continues to be a potential devastating factor to wheat production. This could be attributed to change of races 
and continuous cultivation of wheat cultivars susceptible to stem rust [5]. Stem rust is regarded to be prevalent at lower to mid-altitude areas [10], but it can also develop to severe epidemic levels at higher altitudes if environmental conditions are favorable. Bale and Arsi regions are areas conducive for stem rust development [26]. Particularly, the bimodal rainfall distribution in Bale highlands provides a green bridge between two seasons that could host the pathogen and assist the movement of primary inoculum from one crop to the next. This condition has enhanced the epidemic occurrence of stem rust [2]. In Ethiopia, yield losses due to stem rust have been reported to be in the range of $61-100 \%$ depending on the susceptibility of the variety and environmental conditions [12], [27]. Changes in atmospheric composition and the physical climate, including temperature, rainfall and humidity, will, no doubt, affect the economic importance, geographical distribution and management of rusts of wheat. Currently, the majority of commercial bread wheat cultivars have become susceptible to stem rust and/or yellow rust [25]. Consequently, improved varieties stay in production for about three years or less due to resistance breakdown (resulting from new race development). Little is known about the potential effect of changing atmospheric composition or physical climate on the biology of cereal rust fungi and assessments of climate change impacts on wheat rusts limited. Therefore, this study was conducted with the objective to assess and model the effect of climate variability on wheat stem rust epidemics.

\section{Materials and Methods}

\subsection{Description of the Study Areas}

The study was conducted at two locations, namely Sinana and Kulumsa Agricultural Research Centers, in the Southeastern highlands of Ethiopia during the main cropping season in 2013. Both study areas are located in the Oromia National Regional State and they are representative sites for wheat production for commercial purposes. Sinana Agricultural Research Center (SARC) is characterized by bimodal rainfall forming two wheat growing seasons in a year. The two seasons are locally named after the time of crop harvest. The main season, locally called Bonaa, extends from August to December and the other second season, locally called Ganna extends from March to July. SARC is located at $07^{\circ} 07^{\prime} \mathrm{N}$ latitude and $40^{\circ} 10^{\prime} \mathrm{E}$ longitude at $2400 \mathrm{~m}$ above sea level. The annual total rainfall ranges from 750 to $1000 \mathrm{~mm}$. The main season receives 270 to $550 \mathrm{~mm}$ rainfall, while the short season receives from 250 to $560 \mathrm{~mm}$. The mean annual minimum and maximum temperatures are 9 and $21^{\circ} \mathrm{C}$, respectively. The soil type is dominated by pellic vertisol which is slightly acidic. Kulumsa Agricultural Research Center (KARC) experiences a mono-model season (main season) that extends from June to November. KARC is located at $8^{\circ} 01^{\prime} \mathrm{N}$ latitude and $39^{\circ} 09^{\prime} \mathrm{E}$ longitude at $2200 \mathrm{~m}$ above sea level. Its annual total rainfall is $828 \mathrm{~mm}$. The main season receives $535 \mathrm{~mm}$. The mean annual minimum and maximum temperatures are 9.12 and $22.2^{\circ} \mathrm{C}$, respectively. The soil type is dark clay-loam.

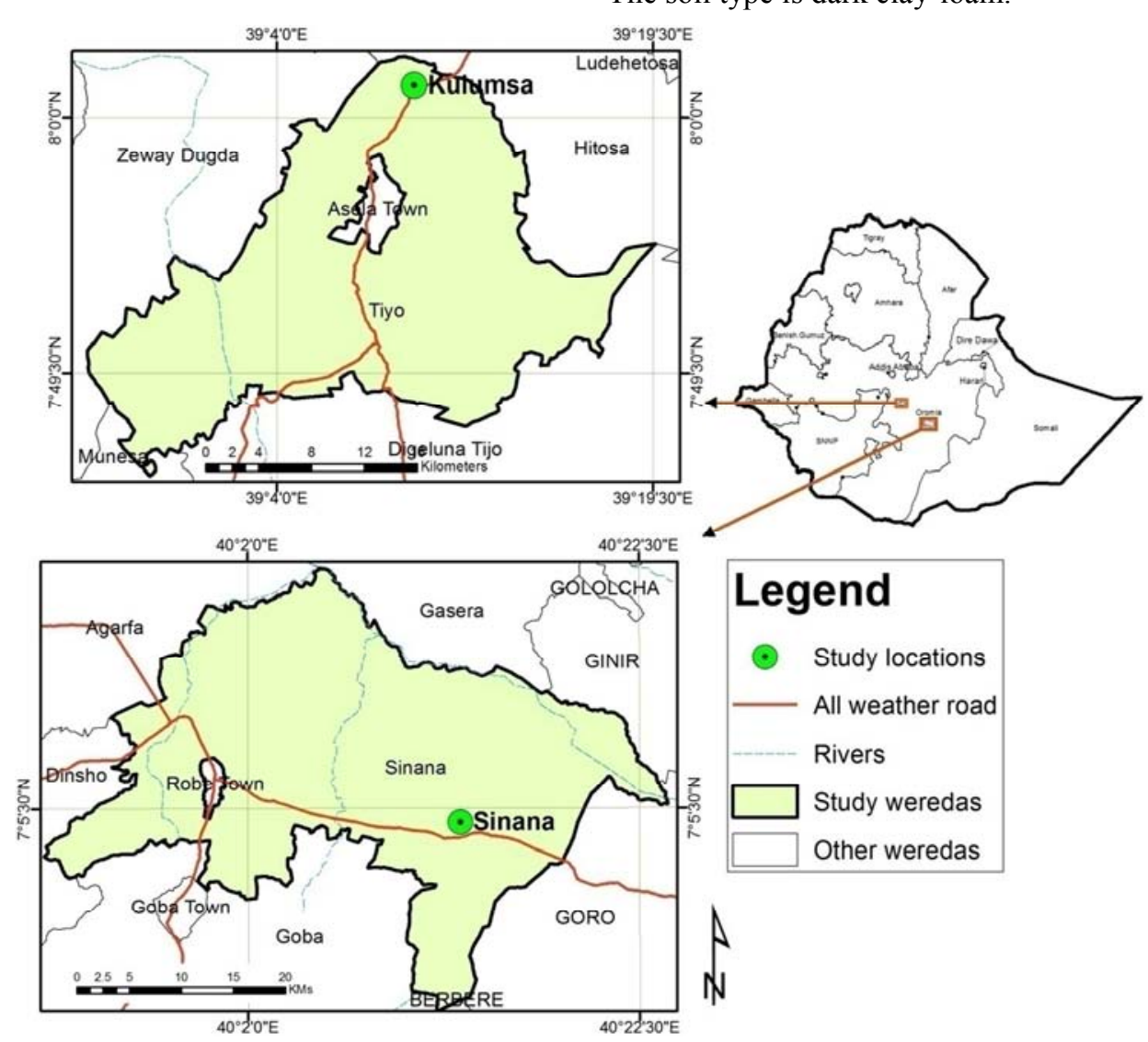

Figure 1. Geographical map showing bread wheat stem rust epidemics study areas of Sinana and Kulumsa, Oromia National Region State, Ethiopia. 


\subsection{Status of Stem Rust on Commercial Bread Wheat Cultivars}

Sinana and Kulumsa were selected for the study because these two locations represent the major wheat growing areas of the country and are characterized by high rainfall with regular stem rust epidemics. The Ethiopian Wheat Rust Trap Nursery (EWRTN) began in 1980 in Ethiopia. Since 1980 EWRTN has been carried out annually in the major wheat growing areas of the country. This activity is a continuous work per year at specified locations (Ambo, Debrezeit, Debreberhan, Holetta, Kulumsa and Sinana) in the country. The main objective of EWRTN is to monitor prevailing virulence of the pathogens causing yellow rust, stem rust and leaf rust. EWRTN is usually planted in the main cropping seasons at locations where rust diseases occur naturally each year. The trap nursery includes different entries which are grouped into four sets, including commercial and candidate varieties of bread and durum wheat, stem rust, leaf rust and yellow rust differential varieties.

Among several commercial cultivars of bread wheat grown in EWRTN, only four popular commercial cultivars
(Kubsa, Madawalabu, Sofumer and Tusie) were selected. These four bread wheat cultivars were widely grown with varying degree of resistance to stem rust epidemics. These cultivars include Madawalabu and Sofumer, which were widely grown since 2000 and moderately resistant to stem rust, while Tusie was widely grown since 1997 and moderately resistant to stem rust and Kubsa was a major cultivar widely grown since 1995 that was susceptible to stem rust. The four cultivars are still under extensive production. The characteristic features of the selected bread wheat cultivars are presented in tabular form (Table 1).

These four commercial cultivars selected for the study were planted in the field in two rows of $0.2 \mathrm{~m}$ spacing between rows and $1 \mathrm{~m}$ long with non-replications. These cultivars have been evaluated in EWRTN at Sinana and Kulumsa Agricultural Research centers during the main cropping season for several consecutive years. Land preparation was done manually as recommended for wheat. Plots were sown manually in rows at a seed rate of $150 \mathrm{~kg} \mathrm{ha}^{-1}$. Fertilizer rates of $41 \mathrm{ha}^{-1} \mathrm{~N}$ and 46 $\mathrm{kg} \mathrm{ha}^{-1} \mathrm{P}_{2} \mathrm{O}_{5}$ was applied at planting. Weeds were controlled two times by hand weeding.

Table 1. Characteristic features of four bread wheat cultivars used for assessing epidemics of stem rust in Sinana and Kulumsa Agricultural Research Centers.

\begin{tabular}{llllllll}
\hline \multirow{2}{*}{ Variety } & \multirow{2}{*}{ Pedigree } & \multicolumn{2}{c}{ Year of release } & Releasing center & \multicolumn{2}{c}{ Reaction to rusts } & \multicolumn{2}{c}{ Yield (tons ha $^{-1}$ ) } \\
\cline { 3 - 7 } & & & Stem rust & Yellow rust & Leaf rust & Research field & Farmers field \\
\hline Kubsa & HAR-1685 & 1995 & KARC & S & S & MR & $5.8-6.3$ \\
Madawalabu & HAR-1480 & 2000 & SARC & MR & R & R & 4.2 \\
Sofumer & HAR-1889 & 2000 & SARC & MR & MR & R & 3.7 \\
Tusie & HAR-1407 & 1997 & KARC & MR & MR & MR & $4-6.5$ \\
\hline
\end{tabular}

$\mathrm{R}=$ resistant, $\mathrm{MR}=$ moderately resistant, $\mathrm{S}=$ susceptible, $\mathrm{NA}=$ not available Source: MoA (Ministry of Agriculture), 1995, 1997 and 2000

\subsection{Collection of Meteorological Data}

The meteorological data for the year 2004-2013 of Sinana and Kulumsa were obtained from the respective weather stations, which are close to the wheat experimental areas. Weather variables data of total monthly rainfall $(\mathrm{mm})$ of each year, mean minimum temperature, mean maximum temperature, and average monthly temperature $\left({ }^{\circ} \mathrm{C}\right)$ reckoned from minimum and maximum temperatures and for Kulumsa average relative humidity (\%) of the cropping seasons were used for the study.

\subsection{Collection of Disease Data}

Stem rust severity data of the four commercial bread wheat cultivars (Kubsa, Madawalabu, Sofumer and Tusie) during 2004-2013 was obtained from Sinana and Kulumsa Agricultural Research Centers, southeastern highlands of Ethiopia. The stem rust data were recorded by estimating percentage of leaf area affected (Modified Cobb Scale) [24] and infection types were recorded periodically at various stages of plant growth, and converted to coefficient of infection (C. I) using the method employed by Loegering [19]. The time and frequency of observations varied from year to year and from site to site, but the present study used the data recorded at early dough stage. Rust severity was assessed from whole plots of each treatment. The sources of inoculum were from naturally occurring stem rust spores.

\subsection{Statistical Analysis}

The relationship of each weather variable with stem rust severity was determined by correlation analyses [30], [17]. Correlation analysis was conducted using SPSS (IBM SPSS Version 20 for Windows, 2011). Variables that indicated a significant correlation $(\mathrm{P} \leq 0.05)$ with stem rust severity were used in regression analyses. Before proceeding to regression analysis, scatter plots of stem rust severity against scores of each independent variable were examined to estimate the type of relationship between variables. In addition, normality tests of the data and residuals and the stability of the variance of the data were examined to determine whether the data are suitable for analysis using the least-squares regression. Stem rust severity for all four bread wheat cultivars for ten years (2004-2013) as the dependent variable, with weather parameters (total monthly rainfall, mean minimum and maximum temperatures, average monthly temperature and relative humidity of the cropping seasons) as independent variables.

Scatter plots suggested linear relationship between stem rust severity and weather variables. Natural logarithm 
transformation of the data was employed to improve the estimation of the parameters in the regression model [21]. Stepwise regression procedure of Minitab evaluates all possible combinations of independent variables by removing and adding variables each time to identify the best prediction based on criteria such as $\mathrm{R}^{2}$, standard deviation and F-statistic of model parameters. Procedures including best subsets, stepwise and multiple regression analyses were used in quantifying relationship between variables [20]. Models were developed based on ten years' data. All possible regressions were calculated using Minitab version 17. Coefficient of determination $\left(R^{2}\right)$ (maximum value) and standard deviation (SD) (minimum value) were used to select the best model to predict stem rust severity [22]. These data were also graphically depicted and r-values were calculated.

\section{Results and Discussion}

\subsection{Reaction of Commercial Wheat Cultivars to Stem Rust}

The terminal stem rust severities assessed on the cultivars Kubsa Madawalabu, Sofumer and Tusie at Sinana and Kulumsa were recorded at early dough stage during 20042013 main cropping seasons. During 2004-2013 main growing season at Sinana and Kulumsa, all of the tested wheat cultivars showed stem rust severities which ranged from 0 to $40 \%$ (Appendix Table 1). The cultivar Madawalabu showed low rust severity that ranged TR-10S at Sinana and TS-15S at Kulumsa. At Sinana, the cultivar Sofumer showed a moderate rust severity that ranged from TMR/MR-30S to high rust severity that ranged from $10 \mathrm{~S}$ $40 \mathrm{~S}$ on this same cultivar at Kulumsa. Similarly, the cultivar Tusie showed high rust severity that ranged from TMS-40S at Sinana and from 10S-40S at Kulumsa. The cultivar Kubsa also showed high rust severity that ranged from TMR/MS-40S at Sinana and from 5S-40S at Kulumsa.

In seasons 2004, 2005, 2007, 2008 and 2013, high disease severities, were observed at Sinana. This demonstrates that Sinana had been very conducive for stem rust epidemic development during these seasons compared to the remaining years (Figure 2). In 2004, 2005, 2006, 2007, 2008 and 2013 growing seasons, two bread wheat cultivars (Tusie and Kubsa) exhibited susceptible infection type at Sinana, while the cultivar Sofumer was highly affected by stem rust at this location during 2013 main cropping season (Figure 2). In 2009, 2010, 2011 and 2012 seasons, low disease severities were observed almost in all tested cultivars at this location, particularly the susceptible cultivar Kubsa had lower disease severities in 2011 and 2012 seasons than the other cultivars. This could be due to the fact that the cultivar became resistant to stem rust as rainfall decreased or the existence of weather conditions that were not conducive for the development of disease. In 2009 main crop growing season, the drought that occurred at Sinana so severely affected plant growth that disease development had no later measurements at this site.

Similarly, in 2004, 2005, 2006, 2007, 2008, 2009, 2010 and 2011 main cropping seasons high disease pressure was observed at Kulumsa. However, lower disease severities were observed in 2012 and 2013 main seasons than other seasons at this location (Figure 3). The cultivar Kubsa was very susceptible to stem rust for ten consecutive years except in 2012 and 2013 main cropping seasons scored low stem rust severity at Kulumsa. This shows that these seasons were not conducive for stem rust development on this cultivar compared to the previous years. However, the present study showed that Kulumsa had more optimum conditions for stem rust epidemics development than Sinana (Figure 2 and 3). This indicates that the condition was very conducive for stem rust disease development at Kulumsa, whereas the condition at Sinana was not as favourable as Kulumsa for the development of stem rust resulting in low disease development at this location.

At both locations, terminal disease severity over years was more on cultivar Kubsa $>$ Tusie $>$ Sofumer $>$ Madawalabu, respectively. The development of stem rust on the cultivar Madawalabu had been very low at both locations for ten consecutive seasons compared to the three other cultivars. This demonstrates that cultivar Madawalabu remained moderately resistant to stem rust, while the three other cultivars were susceptible to stem rust. Similar results were reported [14] that terminal disease severities were reliable indicators of resistance to stem rust in wheat and barley. For instance, previously the cultivar Sofumer and Tusie were moderately resistant to stem rust, but the present study revealed that the two bread wheat cultivars became susceptible to stem rust. This current findings is in agreement with the investigation of [18] whose work indicated that the rate of disease progress depends on the resistance level of cultivars grown

The current findings also revealed that rainfall increased the susceptibility of bread wheat cultivars to stem rust over the last 10 years and vice versa (Figure 2 and 3). This implies that the cultivars might have become resistant to disease as the amount of rainfall decreased or the prevailing weather conditions was not conducive for the development of stem rust epidemics. Among the four bread wheat cultivars, three cultivars showed susceptibility to stem rust except Madawalabu at both locations. None of the cultivars proved to be completely resistant against the pathogen at both locations. This is due to continuous breakdown of resistance by new race formation by the stem rust pathogen under the influence of environmental conditions. Results of the present study also revealed that stem rust development on the four bread wheat cultivars varied from year to year and from place to place. This is probably due to the differences in relative humidity and temperature. Similarly, Jin [16] noted an interaction between genotypes and rust pathotypes, which might have accrued from variation in environmental temperatures. 


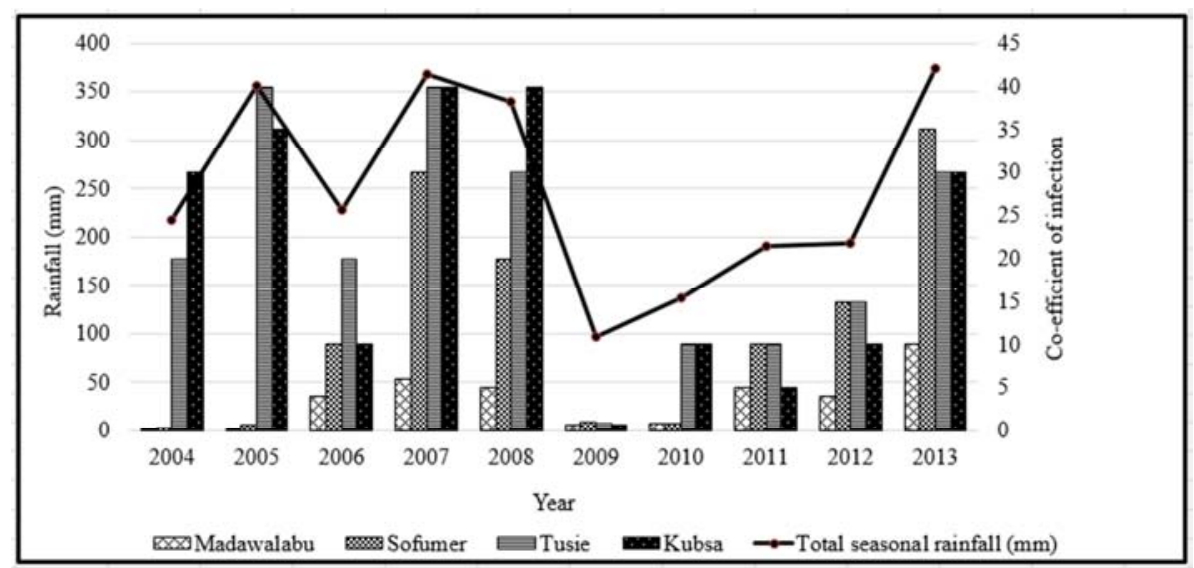

Figure 2. Co-efficient of infection of stem rust as exhibited by four commercial bread wheat cultivars and total seasonal rainfall (mm) during 10 main cropping seasons (2004 to 2013) at Sinana.

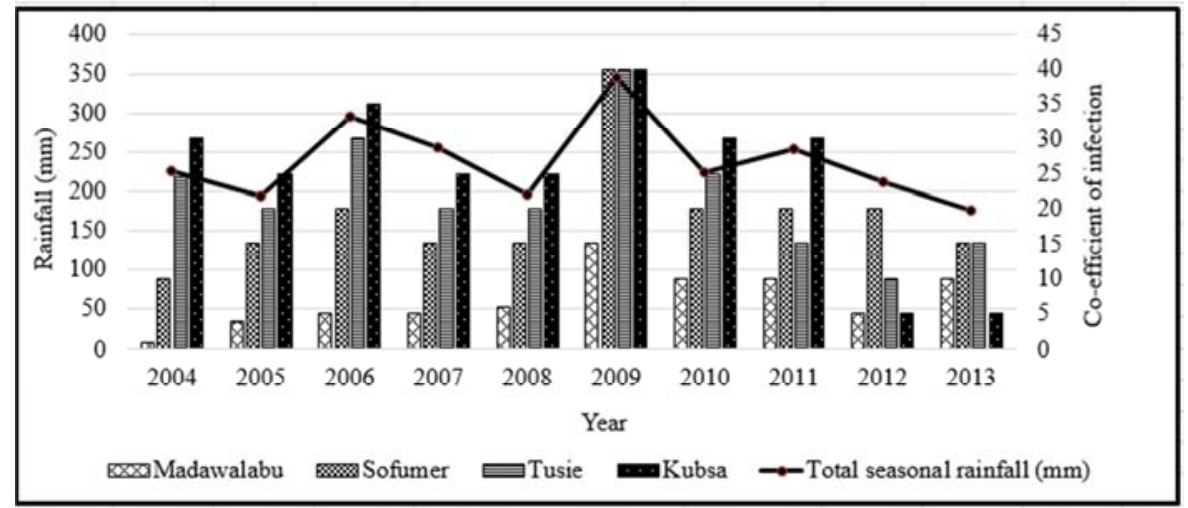

Figure 3. Co-efficient of infection of stem rust as exhibited by four commercial bread wheat cultivars and total seasonal rainfall during 10 main cropping seasons (2004 to 2013) at Kulumsa.

\subsection{Correlation between Stem Rust Severity and Weather Variables}

The correlations between the seasonal mean minimum, maximum and average temperatures, and seasonal total rainfall and seasonal average relative humidity were analyzed with the respective 10 years stem rust severities assessed on the four bread wheat cultivars (Table 2 and 3).

Stem rust severities assessed on Madawalabu and Sofumer cultivars had strong positive correlations $(\mathrm{r}=0.96$ to 0.97 ; $\mathrm{P}$ $\leq 0.01$ ) with total seasonal rainfall at Sinana (Table 2). This implies that stem rust severity increased over years as the amount of rainfall increased. However, there was strong negative correlation that ranged from $(\mathrm{r}=-0.86$ to $-0.99 ; \mathrm{P} \leq$ 0.01 , respectively) of seasonal mean minimum and average temperatures with stem rust severities assessed on the cultivars Tusie and Kubsa at Sinana (Table 2). This shows that monthly mean minimum and average temperatures were not optimum for the development of stem rust compared to the minimum and maximum temperature requirement $(2$ and $30^{\circ} \mathrm{C}$ ) for the development of the stem rust pathogen.

In contrast, stem rust severities recorded on the cultivar Sofumer and Madawalabu had significant negative correlation that ranged from $(\mathrm{r}=-0.93$ to $-0.98 ; \mathrm{P} \leq 0.01)$ with seasonal average relative humidity at Kulumsa (Table
5), whereas strong negative correlation that ranged from $(\mathrm{r}=$ -0.81 to $-0.89 ; \mathrm{P} \leq 0.01$ ) was observed between stem rust severity assessed on cultivar Kubsa and seasonal average temperature and seasonal mean minimum temperature at this location (Table 5). This reflects that monthly average relative humidity, monthly average and mean minimum temperatures were not favourable for stem rust epidemic development at Kulumsa. However, the cultivar Tusie had a significant positive correlation $(\mathrm{r}=0.81 ; \mathrm{P} \leq 0.05)$ with total seasonal rainfall at Kulumsa. This implies that the amount of total rainfall during epidemic period was conducive for the development of stem rust at this location.

The correlation between the seasonal mean maximum temperature and stem rust severity had a positive association but was statistically not significant (Table 2 and 3 ). In the present study, the terminal stem rust severity was strongly and positively correlated with total seasonal rainfall both at Sinana and Kulumsa. However, there was a negative correlation of stem rust severity with seasonal mean minimum and seasonal average temperatures at both locations. At Sinana, the minimum temperature ranged from 8.2 to $9.7^{\circ} \mathrm{C}$ and the average temperature ranged from 14.2 to $14.9^{\circ} \mathrm{C}$, while at Kulumsa minimum temperature ranged from 8.4 to $10.5^{\circ} \mathrm{C}$ and the average temperature ranged from 14.8 - 
$16.9^{\circ} \mathrm{C}$. Similarly, the total rainfall ranged from 97.1 to 373.6 $\mathrm{mm}$ for Sinana and ranged from 76.4-345 mm for Kulumsa. The results of the present study indicated that total seasonal rainfall had a positive effect on the development of wheat stem rust, while seasonal mean minimum and average temperatures and seasonal average relative humidity significantly affected the development of wheat stem rust in the field.

Table 2. Pearson's correlation coefficients between stem rust severity on four different bread wheat cultivars and weather variables at Sinana in the main season.

\begin{tabular}{|c|c|c|c|c|c|}
\hline \multirow{2}{*}{ Weather variable } & \multirow{2}{*}{ Basis of analysis } & \multicolumn{4}{|c|}{ Stem rust severity (\%) } \\
\hline & & Madawalabu & Sofumer & Tusie & Kubsa \\
\hline Minimum temperature & Season & -0.27 & -0.30 & $-0.86 * *$ & $-0.96 * *$ \\
\hline Maximum temperature & Season & 0.45 & 0.56 & 0.33 & 0.48 \\
\hline Average temperature & Season & -0.23 & -0.15 & $-0.99 * *$ & $-0.92 * *$ \\
\hline Total rainfall & Season & $0.96 * *$ & $0.97 * *$ & 0.13 & 0.28 \\
\hline
\end{tabular}

** Correlation is highly significant at $\mathrm{P} \leq 0.01$.

Table 3. Pearson's correlation coefficients between stem rust severity on four different bread wheat cultivars and weather variables at Kulumsa in the main season.

\begin{tabular}{|c|c|c|c|c|c|}
\hline \multirow{2}{*}{ Weather variable } & \multirow{2}{*}{ Basis of analysis } & \multicolumn{4}{|c|}{ Stem rust severity (\%) } \\
\hline & & Madawalabu & Sofumer & Tusie & Kubsa \\
\hline Minimum temperature & Season & -0.01 & -0.24 & -0.56 & $-0.89 * *$ \\
\hline Maximum temperature & Season & 0.05 & 0.07 & 0.25 & 0.57 \\
\hline Average temperature & Season & -0.03 & -0.25 & -0.55 & $-0.81 * *$ \\
\hline Total rainfall & Season & 0.36 & 0.57 & $0.81 * *$ & 0.34 \\
\hline Average RH & Season & $-0.98 * *$ & $-0.93 * *$ & -0.18 & -0.05 \\
\hline
\end{tabular}

**Correlation is highly significant at $P \leq 0.01$.

\subsection{Analysis of Disease and Meteorological Data}

The disease severity data of each bread wheat cultivar were regressed as a function of weather variables. The disease data showed a high degree of variation and appeared misleading because the disease was not observed in year 2009 at Sinana. Kulumsa had more optimum conditions for stem rust epidemics development than Sinana. In seasons of 2012 and 2013, low disease severities were observed at Kulumsa. The development of stem rust on the cultivar Madawalabu had been very low at both locations over ten consecutive seasons compared to other cultivars.

Analysis of meteorological data at Sinana showed that minimum, maximum and average temperatures and rainfall ranged from 8.2-9.7 $\left({ }^{\circ} \mathrm{C}\right), 19.7-20.7\left({ }^{\circ} \mathrm{C}\right), 14.2-14.9\left({ }^{\circ} \mathrm{C}\right)$ and 97.1-373.6 (mm), respectively. Similarly, at Kulumsa the parameters (minimum, maximum and average temperature, rainfall and relative humidity) ranged from $8.4-10.5\left({ }^{\circ} \mathrm{C}\right), 21$ $23\left({ }^{\circ} \mathrm{C}\right), 14.8-16.9\left({ }^{\circ} \mathrm{C}\right), 76.4-345(\mathrm{~mm})$ and 51-64 $(\%)$, respectively.

\subsection{Multiple Regression Analysis of Disease Data}

The regression analysis for the cultivar Madawalabu at Sinana showed a positive effect of total seasonal rainfall on wheat stem rust severity. This result indicated that a single unit of rainfall increment resulted in stem rust severity increment of about $5 \%$ (Table 4). However, a strong negative relationship was observed between average relative humidity and stem rust severity at Kulumsa. This reflects that $1 \%$ rise in average relative humidity above the optimum resulted in stem rust severity reduction of about $2.02 \%$ (Table 4 ). These findings are in line with Peterson [23] who reported that stem rust is favored by warm to hot days with six or more hours of moisture and favourable temperature and develops to devastating levels, if such conditions prevail during early reproductive phase prior to dough stage of the crop growth.

The regression analysis for Sofumer depicted same to Madawalabu at both study locations, which showed positive impacts of total seasonal rainfall on stem rust severity at Sinana, while a negative impact of average relative humidity on stem rust severity at Kulumsa (Table 4). This implies that a single unit of rainfall increment helped for successful infection development. A rise by $1 \%$ in average relative humidity above the optimum resulted in stem rust severity reduction of about $2.85 \%$ (Table 4 ).

The regression analysis on Tusie at Sinana revealed negative impacts of seasonal mean minimum and average temperatures on stem rust severity. This demonstrates that every degree Celsius increment in monthly mean minimum and average temperature resulted in stem rust severity increment of about 1.85 and $48.8 \%$, respectively (Table 4 ). However, there were positive impacts of total seasonal rainfall on stem rust severity at Kulumsa. This result showed that a single unit of rainfall increment resulted in stem rust severity increment of about $18 \%$ at Kulumsa (Table 4).

The regression analysis for Kubsa at both locations depicted negative impacts of seasonal mean minimum and average temperatures on stem rust severity. This result showed that an increase by $1^{\circ} \mathrm{C}$ in monthly mean minimum and average temperatures resulted a corresponding stem rust severity reduction of about 15.3 and $24.9 \%$ for Sinana and 21 and $16.6 \%$ for Kulumsa (Table 4 ). 
Table 4. Multiple regression analysis of stem rust of wheat on Kubsa, Madawalabu, Sofumer, and Tusie cultivars at two locations.

\begin{tabular}{lll}
\hline Location & $\mathbf{R}^{2}$ & Regression model \\
\hline \multirow{4}{*}{ Sinana } & 97.5 & $\mathrm{Y}(\mathrm{K})=50.7-15.3 \mathrm{~T}_{\min }+0.43 \mathrm{~T}_{\max }-24.9 \mathrm{~T}_{\text {ave }}+0.02 \mathrm{RF}$ \\
& 97.4 & $\mathrm{Y}(\mathrm{M})=58.7-0.24 \mathrm{~T}_{\min }-1.03 \mathrm{~T}_{\max }-2.75 \mathrm{~T}_{\text {ave }}+0.05 \mathrm{RF}$ \\
& 98.8 & $\mathrm{Y}(\mathrm{S})=-45.7-5.53 \mathrm{~T}_{\min }-0.73 \mathrm{~T}_{\max }+6.77 \mathrm{~T}_{\text {ave }}+0.12 \mathrm{RF}$ \\
& 98.4 & $\mathrm{Y}(\mathrm{T})=75.8-1.85 \mathrm{~T}_{\min }-0.43 \mathrm{~T}_{\max }-48.7 \mathrm{~T}_{\text {ave }}+0.06 \mathrm{RF}$ \\
Kulumsa & $\mathrm{Y}(\mathrm{K})=38.1-0.21 \mathrm{~T}_{\min }+7.92 \mathrm{~T}_{\max }-16.6 \mathrm{~T}_{\text {ave }}-0.08 \mathrm{RF}+0.13 \mathrm{RH}$ \\
& 95.6 & $\mathrm{Y}(\mathrm{M})=75.1+2.92 \mathrm{~T}_{\min }+1.05 \mathrm{~T}_{\max }-0.07 \mathrm{~T}_{\text {ave }}+0.02 \mathrm{RF}-2.02 \mathrm{RH}$ \\
& 97.2 & $\mathrm{Y}(\mathrm{S})=69-3.43 \mathrm{~T}_{\min }-1.82 \mathrm{~T}_{\max }+10.2 \mathrm{~T}_{\text {ave }}+0.10 \mathrm{RF}-2.85 \mathrm{RH}$ \\
& 94.6 & $\mathrm{Y}(\mathrm{T})=-25-0.9 \mathrm{~T}_{\min }+0.98 \mathrm{~T}_{\max }+12.1 \mathrm{~T}_{\text {ave }}+0.18 \mathrm{RF}+0.51 \mathrm{RH}$ \\
\hline
\end{tabular}

$\mathrm{Y}(\mathrm{M})=$ disease severity assessed on Madawalabu, $\mathrm{Y}(\mathrm{S})=$ disease severity assessed on Sofumer, $\mathrm{Y}(\mathrm{T})=$ disease severity on Tusie, $\mathrm{Y}(\mathrm{K})=$ disease severity assessed on Kubsa, $\mathrm{T}_{\min }=$ minimum temperature $\left({ }^{\circ} \mathrm{C}\right), \mathrm{T}_{\max }=$ maximum temperature $\left({ }^{\circ} \mathrm{C}\right), \mathrm{T}_{\text {ave }}=$ average temperature $\left({ }^{\circ} \mathrm{C}\right), \mathrm{RF}=\mathrm{Rainfall}(\mathrm{mm}), \mathrm{RH}=\mathrm{Relative}$ humidity (\%), $\mathrm{R}^{2}=$ Coefficient of determination.

\subsection{Interaction of Individual Weather Variables and the Stem Rust Severity}

The research results in the present study showed that temperature (minimum, maximum and average); rainfall and relative humidity interacted simultaneously in nature and contributed collectively to making the environment favorable for the stem rust development, which showed existence of multi-collinearity among them (Appendix Table 2 and 3). When the effects of these weather factors were assessed individually, it was found that there existed no significant positive impact between stem rust development and individual weather factors except with a few weather variables. If one of these weather factors was missed, the disease would not develop. However, if disease develops, its severity fluctuates with changing environmental conditions.

\subsubsection{Effect of Temperature on Stem Rust Epidemics}

The stem rust development was investigated with temperature as a single factor against all the cultivars. It was found that the temperature solely was not responsible for successful infection. At both locations, the interaction of temperature with disease severity was shown (Appendix Figure 1, 2, 3, 4, 5 and 6), but none of the cultivars had positive interaction except the maximum temperature, which was not also significant at these two locations with $\mathrm{R}^{2}$-values ranging from 0.0008 to 0.982 . Furthermore, the regression analysis showed that there was a negative impact of temperature on disease development. This shows that monthly temperatures were not conducive for the epidemic development of stem rust at both locations. Similarly, it was previously reported that several environmental variables were affected the production, dispersal, and survival of uredospores [13]. Generally, temperature alone could not help in disease development, but it also required suitable amount of water or dew.

\subsubsection{Effect of Relative Humidity on Stem Rust Epidemics}

Relative humidity plays an important role in the penetration of haustorium of fungus as it makes the leaf tender due to moisture content. When assessed in pooled disease data at Kulumsa, disease development showed no dependence on a single factor as the $\mathrm{R}^{2}$ values were between 0.034 and 0.955 (Appendix Figure 7) for all the four cultivars, but at Sinana, relative humidity data were not recorded for a long period because the instrument for relative humidity measurement was not functional, so no data were collected for this location. The regression analysis showed that there was a negative impact of relative humidity on disease development. This result indicated that the monthly average relative humidity during the crop growing season at Kulumsa was not favourable for pathogen development. Similarly, Bolton [3] noted that moisture affects spore germination, infection, and survival of the uredospores, requires at least $3 \mathrm{hrs}$ of continuous moisture on the plant surfaces to germinate and to infect plants.

\subsubsection{Effect of Rainfall on Stem Rust Epidemics}

Rainfall is an important factor for spore deposition during long distance dispersal of the spores and the regression analysis showed that there was a positive effect of rainfall on disease development at both locations. This current result reflected that the monthly total rainfalls at these locations during the crop growing season were very conducive for the pathogen requirement for its growth and development. These findings are in agreement with Daamen [9] who reported that the presence of strong association between severity and hydric variables, such as precipitation and relative humidity was observed as previously recorded. For both locations, the $\mathrm{R}^{2}$ values occurred between 0.018 and 0.955 (Appendix Figure 8 and 9).

\section{Model Development}

The regression analyses of weather variables and stem rust severity resulted in the development of numerous two and three variable equations (Table 4). Based on standard deviation and maximum coefficient of determination $\left(\mathrm{R}^{2}\right)$, the best subsets regression procedure [20] generated a number of regression models (Table 5 and 6). The program selected a one-predictor model with the largest $\mathrm{R}^{2}$-value. Next, two-predictor models with significantly larger $\mathrm{R}^{2}$ were listed. This process continued until all the specified predictors were selected. Each row represents a specific model with the respective $\mathrm{SD}$ and $\mathrm{R}^{2}$ values (Table 5 and 6).

In the commercial bread wheat cultivar Madawalabu, the best one-variable model used total rainfall $\left(\mathrm{R}^{2}=93.1 \%\right)$ at Sinana. The second best one-variable model used the maximum temperature $\left(\mathrm{R}^{2}=33.2 \%\right)$. The best two-variable 
model used the minimum temperature and the total rainfall $\left(\mathrm{R}^{2}=97.1 \%\right)$. Similarly, at Kulumsa in the cultivar Madawalabu, the best one-variable model used average relative humidity $\left(\mathrm{R}^{2}=95.5 \%\right)$. The second best one-variable model used total rainfall $\left(\mathrm{R}^{2}=30.5 \%\right)$. The best two-variable model used average temperature and average relative humidity $\left(\mathrm{R}^{2}=96.3 \%\right)$. For both locations, the different models listed for the remaining cultivars could be visualized in the same way (Table 5 and 6). In the two bread wheat cultivars (Madawalabu and Sofumer) at Sinana, total rainfall was selected as the best one-predictor model, whereas in the cultivars Tusie and Kubsa, the minimum temperature was selected as the best one-predictor model (Table 5). Later, the total rainfall and the minimum temperature were considered as the best predictors $\left(\mathrm{R}^{2}=95.6\right.$ and $70.1 \%$, respectively), at Sinana. The best two-variable models usually included the minimum temperature and the total rainfall (Table 5).

Likewise, at Kulumsa in the cultivar Madawalabu and
Sofumer the average relative humidity was selected as the best one-predictor model, while in the cultivar Sofumer and Kubsa, the total rainfall and the minimum temperature were selected as the best one-predictor model, respectively (Table 6). Later on, the average relative humidity and the minimum temperature were considered as the best predictors $\left(\mathrm{R}^{2}=95.5\right.$ and $80.9 \%$, respectively) at Kulumsa. The best two-variable model included the average temperature and the average relative humidity (Table 6). At Sinana, the stepwise regression procedure consistently selected a simple linear model with the total rainfall as the best predictor for the cultivars Madawalabu and Sofumer, whereas the minimum temperature for the cultivars Tusie and Kubsa (Table 5). On the contrary, at Kulumsa the stepwise regression consistently yielded a simple linear model with the average relative humidity as the best predictor for the cultivars Madawalabu and Sofumer, while the total rainfall and the minimum temperature for cultivars Tusie and Kubsa, respectively (Table 6).

Table 5. Models using different predictors with respective standard deviation and $R$-square values as generated by best subsets regression procedures for four commercial bread wheat cultivars at Sinana.

\begin{tabular}{|c|c|c|}
\hline $\mathbf{R}^{2}$ & SD & Predictors $^{1}$ \\
\hline \multicolumn{3}{|c|}{ Madawalabu } \\
\hline 93.1 & 1.34 & Total rainfall (mm) \\
\hline 33.2 & 4.56 & Maximum temperature \\
\hline 93.5 & 1.39 & Minimum temperature + Total rainfall \\
\hline 96.9 & 1.03 & Maximum temperature + Average temperature + Total rainfall \\
\hline \multicolumn{3}{|c|}{ Sofumer } \\
\hline 31.3 & 9.77 & Maximum temperature \\
\hline 97.1 & 2.22 & Minimum temperature + Total rainfall \\
\hline 96.5 & 2.46 & Average temperature + Total rainfall \\
\hline 97.7 & 2.17 & Minimum temperature + Maximum temperature + Total rainfall \\
\hline \multicolumn{3}{|r|}{ e } \\
\hline 63.6 & 9.47 & Minimum temperature $\left({ }^{\circ} \mathrm{C}\right)$ \\
\hline 62.1 & 9.67 & Average temperature \\
\hline 68.5 & 9.43 & Maximum temperature + Average temperature \\
\hline 73.4 & 9.36 & Minimum temperature + Maximum temperature + Average temperature \\
\hline \multicolumn{3}{|r|}{ 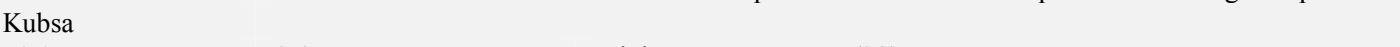 } \\
\hline 70.1 & 9.45 & Minimum temperature $\left({ }^{\circ} \mathrm{C}\right)$ \\
\hline 56.5 & 11.39 & Average temperature \\
\hline 74.6 & 9.38 & Minimum temperature + Total rainfall \\
\hline 70.9 & 9.96 & Minimum temperature + Average temperature \\
\hline 74.6 & 10.04 & Minimum temperature + Maximum temperature + Total rainfall \\
\hline
\end{tabular}

${ }^{1}$ Predictors are weather variables collected at Sinana research station; response variables are assessed stem rust severity (\%) on Madawalabu, Sofumer, Tusie and Kubsa from 2004-2013.

Table 6. Models using different predictors with respective standard deviation and R-square values as generated by best subsets regression procedures for four commercial bread wheat cultivars at Kulumsa.

\begin{tabular}{lll}
\hline $\mathbf{R}^{2}$ & SD & Predictors $^{\mathbf{1}}$ \\
\hline Madawalabu & & \\
95.5 & 1.94 & Average relative humidity $(\%)$ \\
30.5 & 8.57 & Total rainfall $(\mathrm{mm})$ \\
96.4 & 1.85 & Minimum temperature + Average relative humidity \\
96.3 & 1.88 & Average temperature + Average relative humidity \\
96.6 & 1.96 & Minimum temperature + Maximum temperature + Average relative humidity \\
96.5 & 1.97 & Minimum temperature + Total rainfall + Average relative humidity \\
Sofumer & & \\
87.2 & 5.45 & Average relative humidity $(\%)$ \\
32.9 & 7.49 & Total rainfall (mm) \\
90.5 & 5.03 & Total rainfall + Average relative humidity \\
\hline
\end{tabular}




\begin{tabular}{lll}
\hline $\mathbf{R}^{2}$ & SD & Predictors $^{1}$ \\
\hline 89.1 & 5.39 & Average temperature + Average relative humidity \\
90.7 & 5.37 & Average temperature + Total rainfall + Average relative humidity \\
90.7 & 5.37 & Minimum temperature + Total rainfall + Average relative humidity \\
Tusie & & \\
65.3 & 5.55 & Total rainfall $(\mathrm{mm})$ \\
31.1 & 7.82 & Minimum temperature \\
73.7 & 5.16 & Maximum temperature + Total rainfall \\
68.9 & 5.65 & Total rainfall + Average relative humidity \\
78.3 & 5.06 & Maximum temperature + Total rainfall + Average relative humidity \\
74.8 & 5.45 & Maximum temperature + Average temperature + Total rainfall \\
Kubsa & & \\
80.9 & 5.33 & Minimum temperature $\left({ }^{\circ} \mathrm{C}\right)$ \\
65.1 & 7.21 & Average temperature \\
88.2 & 4.49 & Maximum temperature + Average temperature \\
86.8 & 4.75 & Minimum temperature + Maximum temperature \\
92.0 & 3.99 & Maximum temperature + Average temperature + Total rainfall \\
89.3 & 4.60 & Maximum temperature + Average temperature + Average relative humidity \\
\hline
\end{tabular}

${ }^{1}$ Predictors are weather variables collected at Kulumsa research station; response variables are assessed stem rust severity (\%) on Madawalabu, Sofumer, Tusie and Kubsa from 2004-2013.

The statistical models generated by stepwise regression for different bread wheat cultivars at Sinana and Kulumsa are presented (Table 7 and 8). The significance of the selected predictors was determined by simple regression analyses and the resulting P-values are shown (Table 7 and 8).

The model with total rainfall and minimum temperature as predictors yielded $\mathrm{R}^{2}$-values ranging from $93.1 \%$ for the cultivar Madawalabu to $95.6 \%$ for Sofumer, while $63.6 \%$ for the cultivar Tusie and $70.1 \%$ for Kubsa (Table 7). Similarly, the model with relative humidity as predictor generated $\mathrm{R}^{2}$ values ranging from $87.2 \%$ for the cultivar Sofumer to $95.5 \%$ for the cultivar Madawalabu (Table 8). For cultivars Tusie and Kubsa, the total rainfall and the minimum temperature as predictors gave $\mathrm{R}^{2}$-values ranging from 65.2 to $80.9 \%$, respectively. Estimates of regression slopes (parameter $\mathrm{b}$ ) for the effects of total rainfall, average relative humidity and minimum temperature on stem rust epidemics were significant and ranged from $-26.73(\mathrm{P} \leq 0.01)$ for the cultivar Kubsa to 0.05 ( $\mathrm{P} \leq 0.01)$ on cultivar Madawalabu (Table 7), and also ranged from $-13.57(\mathrm{P} \leq 0.01)$ for the cultivar Kubsa to $0.12(\mathrm{P} \leq 0.01)$ for the cultivar Tusie (Table 8$)$.

Table 71. Statistical values on models generated by stepwise regression for stem rust severity on weather variables for different bread wheat cultivars at Sinana.

\begin{tabular}{lllll}
\hline Bread wheat & Coefficients & Constant (P-value) & R $^{2}$ & \\
\hline Madawalabu $^{\mathrm{a}}$ & $0.05(0.000)^{1}$ & $-4.21(0.002)$ & 93.1 & \\
Sofumer $^{\mathrm{a}}$ & $0.12(0.000)$ & $-11.51(0.000)$ & 95.6 & \\
Tusie $^{\mathrm{b}}$ & $-23.16(0.006)$ & $24.60(0.004)$ & 63.6 & 2.58 \\
Kubsa $^{\mathrm{b}}$ & $-26.73(0.003)$ & $57.20(0.002)$ & 70.1 & 9.47 \\
\hline
\end{tabular}

${ }^{1}$ Numbers in parenthesis are P-values.

${ }^{a}$ In two varieties total rainfall was used as regressors

${ }^{\mathrm{b}}$ In two other varieties minimum temperature was used as regressors

Table 8. Statistical values on models generated by stepwise regression for stem rust severity on weather variables for different bread wheat cultivars at Kulumsa.

\begin{tabular}{lllll}
\hline Bread wheat & Coefficients & Constant (P-value) & R $^{2}$ & \\
\hline Madawalabu $^{2}$ & $-2.07(0.000)^{1}$ & $30.71(0.000)$ & 95.5 & \\
Sofumer $^{2}$ & $-3.28(0.000)$ & $20.80(0.000)$ & 87.2 & 1.94 \\
Tusie $^{3}$ & $0.12(0.005)$ & $-5.36(0.048)$ & 65.2 & 5.45 \\
Kubsa $^{4}$ & $-13.57(0.000)$ & $49.70(0.000)$ & 80.9 & 5.55 \\
\hline
\end{tabular}

${ }^{1}$ Numbers in parenthesis are P-values.

${ }^{2}$ In two varieties average relative humidity was used as regressors.

${ }^{3,4}$ Tusie and Kubsa total rainfall and minimum temperature were used as regressors, respectively.

The linear regression models fitted to the stem rust severity on weather variables in the four bread wheat cultivars were selected using different regression procedures (Figure 4 and 5). Campell and Madden [4] described that the observed data randomly scattered around the prediction line, presenting a supportive evidence how the fitted model in the current study is reasonable.
The present study revealed that the total seasonal rainfall, the seasonal average relative humidity and the seasonal mean minimum temperature were selected as predictors in all cultivars at Sinana and Kulumsa. However, seasonal average temperature was not selected as a predictor in the present study. This implies that the average temperature does not mean that it had no significant effect on the epidemics of 
stem rust development. This variable was significantly correlated with stem rust severities assessed on bread wheat cultivars. This reflects that the average temperature influences the epidemic development of stem rust. Although positive correlation between the seasonal mean maximum temperature and stem rust severity was observed in the present study, but it was not statistically significant (Table 2 and 3). The possible reason for lack of correlation between stem rust severity and the seasonal mean maximum temperature might have not reached the level of maximum temperature required by stem rust for epidemic development.

The selection of total rainfall, average relative humidity and minimum temperature as predictors in some bread wheat cultivars does not mean that the other weather variables did not significantly affect stem rust development. All these variables were significantly correlated $(\mathrm{P} \leq 0.01)$ with stem rust severity assessed on the four bread wheat cultivars. On the other hand, the maximum temperature as a second choice in two bread wheat cultivars (Madawalabu and Sofumer) accounted for 31.3 to $33.2 \%$ of the variation in stem rust severity, whereas the average temperature also was considered as a second choice in the two cultivars (Tusie and Kubsa), which accounted for 56.5 to $62.1 \%$ of the variation in stem rust severity (Table 5). Similarly, the total rainfall as a second choice in the cultivars Madawalabu and Sofumer accounted for 30.5 to $32.9 \%$ of the variation in stem rust severity, while the minimum temperature and the average temperature as a second choice for cultivars Tusie and Kubsa, which accounted for 31.1 to $65 \%$ of variation in stem rust severity (Table 6). Moreover, total seasonal rainfall explained $95.6 \%$ of the variation in the stem rust severity recorded in the cultivar Sofumer at Sinana, whereas the seasonal average relative humidity explained $95.5 \%$ of the variation in stem rust severity recorded for the cultivar Madawalabu at Kulumsa. Both these variables were selected as the best predictors by stepwise regression procedure (Tables 7 and 8). The present study showed that, in addition to the total rainfall at Sinana, the minimum and the average temperatures, in addition to average relative humidity and average temperature and total rainfall are also important in affecting stem rust severity at Kulumsa.

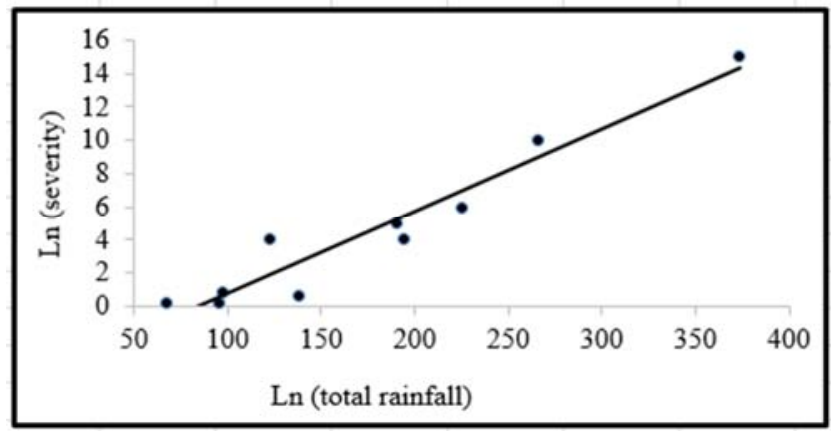

A. Madawalabu: $\operatorname{Ln}(\mathrm{Y})=0.05 \ln (\mathrm{X})-4.21 ; \mathrm{R} 2=0.93$

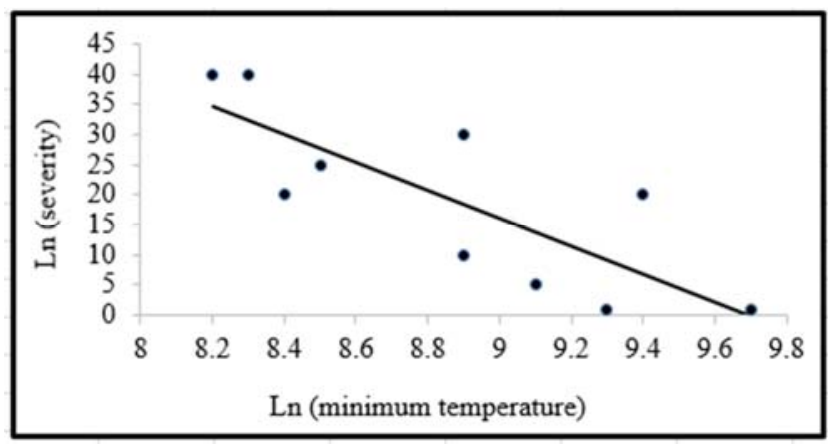

B. Tusie: $\operatorname{Ln}(\mathrm{Y})=-23.16 \ln (\mathrm{X})-22.6 ; \mathrm{R} 2=0.63$

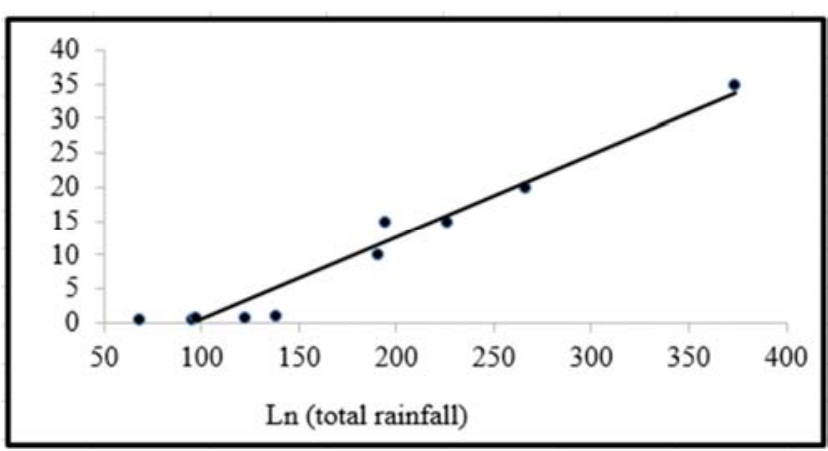

C. Sofumer: $\operatorname{Ln}(\mathrm{Y})=0.12 \ln (\mathrm{X})-11.51 ; \mathrm{R} 2=0.95$

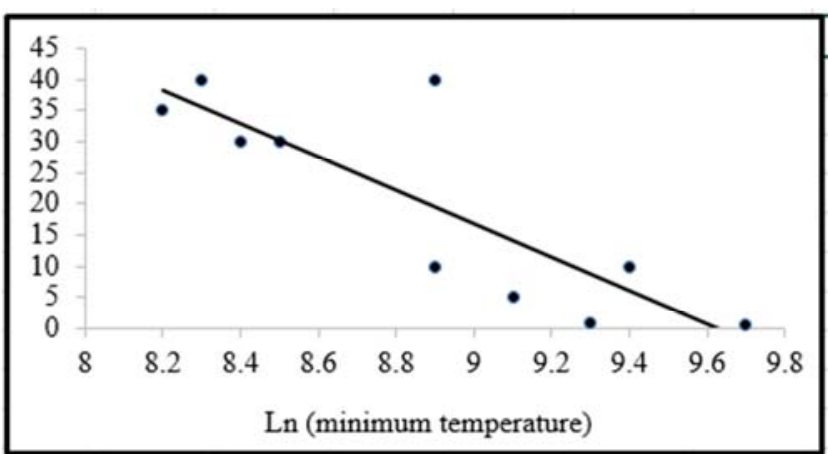

D. Kubsa: $\operatorname{Ln}(\mathrm{Y})=-26.73 \ln (\mathrm{X})+25.2 ; \mathrm{R} 2=0.70$

Figure 4. Linear regression model fitted to the severity of wheat stem rust on the weather variables for four bread wheat cultivars at Sinana.

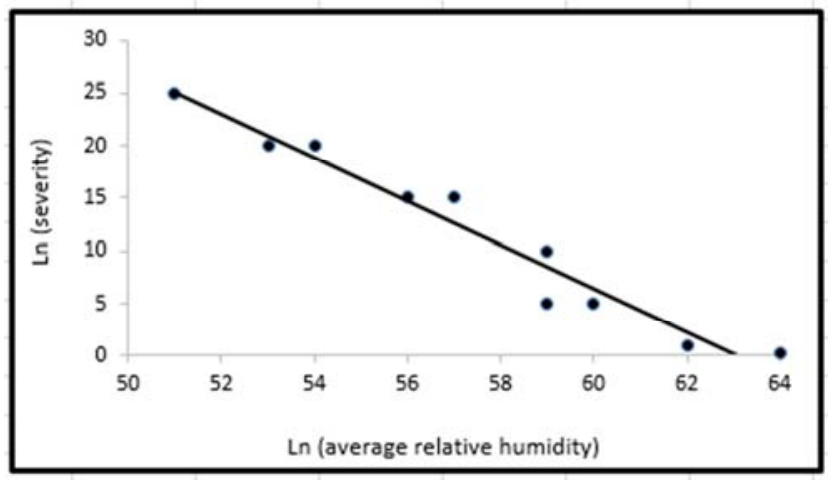

A. Madawalabu: $\operatorname{Ln}(\mathrm{Y})=-2.07 \ln (\mathrm{X})+13.7 ; \mathrm{R} 2=0.95$ 


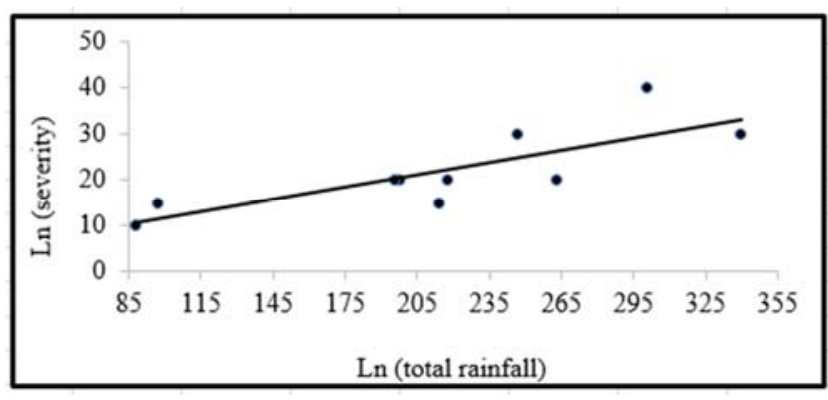

B. Tusie: $\operatorname{Ln}(Y)=0.12 \ln (X)-5.36 ; R^{2}=0.65$

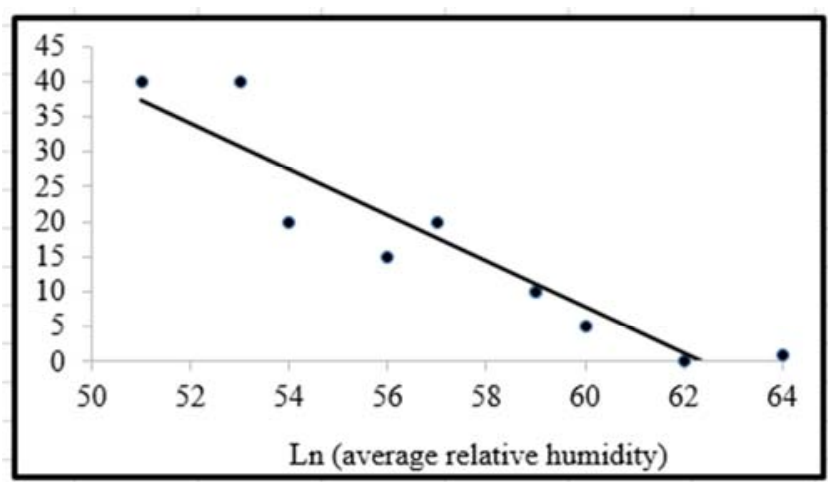

C. Sofumer: $\operatorname{Ln}(\mathrm{Y})=-3.28 \ln (\mathrm{X})+20.8 ; \mathrm{R} 2=0.87$

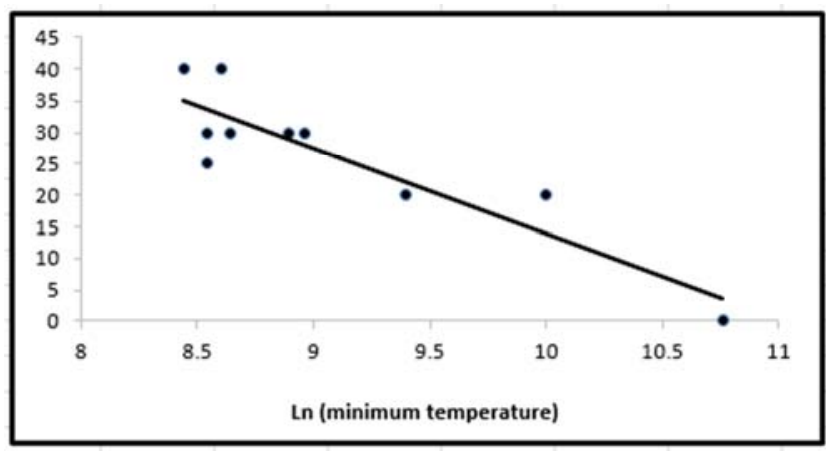

D. Kubsa: $\operatorname{Ln}(\mathrm{Y})=-13.57 \ln (\mathrm{X})+14.7 ; \mathrm{R} 2=0.81$

Figure 5. Linear regression model fitted to the severity of wheat stem rust on the weather variables for four bread wheat cultivars at Kulumsa.

Based on the four commercially known bread wheat cultivars that were used, the present study revealed that the linear regression models indicated that increasing the ln (total rainfall) by a single unit resulted in an increase in $\ln$ (stem rust severity) between 0.05 in Madawalabu and 0.12 in Sofumer. In a related study, Singh [28] described that rainfall favours disease by scrubbing spores from the air, depositing them on the plants and increasing the humidity. Increasing the $\ln$ (minimum temperature) by $1{ }^{\circ} \mathrm{C}$ resulted in a decrease in $\ln$ (stem rust severity) by about $23.16 \%$ in Tusie and by $26.73 \%$ in Kubsa. The change in temperature due to rain will influence disease progress [28]. The models ascribed 63, 70, 93 and $95 \%$ of the variation in observed values of disease severity to the total rainfall the cultivars Madawalabu and Sofumer and minimum temperature in the cultivars Tusie and Kubsa, respectively. On the other hand, at Kulumsa the linear models indicated that increasing the $\ln$ (average relative humidity) by $1 \%$ resulted in decrease in $\ln$ (stem rust severity) between $2.07 \%$ in Madawalabu and 3.28\% in Sofumer. Singh [28] reported that high humidity restricts spore movement.

On the contrary, increasing the $\ln$ (total rainfall) by a single unit resulted in an increase in $\ln$ (stem rust severity) by about $12 \%$ in Tusie. This shows that the total monthly rainfall during the main season was conducive for stem rust development on the cultivar Tusie. At this location, every one degree Celsius increment in $\ln$ (minimum temperature) above the optimum resulted in decrease in $\ln$ (stem rust severity) by about $13.57 \%$ in Kubsa. The models gave 65, 81, 87 and $95 \%$ variation in observed values of $\ln$ (stem rust severity) to the relative humidity and the minimum temperature in the cultivars Madawalabu, Sofumer, Tusie and Kubsa, respectively.

Results of the present study showed that multiple regression models combining the minimum temperature with the model using average temperature were not selected as the best predictor (Tables 5 and 6 ). In most cases, addition of the average temperature to the model minimum temperature could not improve the value of $\mathrm{R}^{2}$ and standard deviation. Moreover, multiple regression models did not explain very well when combining variables in a single model. However, slight improvement observed in $\mathrm{R}^{2}$-values resulting from consequent multiple regressions analyses showed that using the average temperature with the minimum temperature variables revealed later there was not significant contribution observed when collectively treated.

The cultivar Kubsa is presented for demonstration. Multiple regressions output from fitting the minimum temperature and the average temperature on stem rust severity in Kubsa at both locations on disease severity is depicted (Tables 9 and 10). The best fit in the cultivar Kubsa was minimum temperature $\left(\mathrm{R}^{2}=70.1 \%\right)$ and average temperature was a second choice with $\mathrm{R}^{2}=56.5 \%$ at Sinana (Table 9). Likewise, the best fit again in the variety Kubsa was minimum temperature $\left(\mathrm{R}^{2}=80.9 \%\right)$ and average temperature was the second choice with $\mathrm{R}^{2}=65.1 \%$ at Kulumsa (Table 10). The inclusion of the average temperature in the model not only reduced the significance of the minimum temperature $(\mathrm{P} \leq 0.01)$ when used alone to 0.219 , but also the average temperature itself did not have any significant effect on the regression at both locations (Tables 9 and 10). However, when considered alone in simple linear regression analyses the average temperature resulted in a significant $(\mathrm{P} \leq 0.01)$ model at both locations. The present study showed that the irrelevance of using both variables in a single model, but they generated a significant model when treated separately.

An increase in stem rust severity was observed in the present study at both locations as the total seasonal rainfall increased, while reduction in stem rust severity occurred at these locations as the seasonal mean minimum temperature and the seasonal average relative humidity increased. The stem rust severity increased linearly with the total seasonal rainfall at both locations and ranged from 97.1 to $373.6 \mathrm{~mm}$ (at Sinana) 
and from 76.4 to $345 \mathrm{~mm}$ (at Kulumsa), respectively. Stem rust severity decreased linearly with increase in the seasonal mean minimum temperature from 8.2 to $9.7^{\circ} \mathrm{C}$ at Sinana. At Kulumsa, stem rust severity decreased linearly with increase in the seasonal average relative humidity from 51 to $64 \%$ and the seasonal mean minimum temperature from 8.4 to $10.5^{\circ} \mathrm{C}$, respectively. The ranges in mean values for maximum temperature from 19.7 to $20.7^{\circ} \mathrm{C}$, and from 21 to $23^{\circ} \mathrm{C}$, at Sinana and Kulumsa, respectively, were not that much high compared to the maximum temperature stem rust requirement for its growth and development. In a related study, Couture and Sutton [6] reported that low temperatures $\left(<9.50^{\circ} \mathrm{C}\right)$ are known to retard production and release of spores of some fungi in other crops.

Table 9. Analysis of variance output for simple and multiple linear regressions of natural logarithm of stem rust severity on the average temperature and the minimum temperature separately or together using the variety Kubsa at Sinana.

\begin{tabular}{|c|c|c|c|c|c|c|c|c|c|c|}
\hline Source & $\begin{array}{l}\text { Degree of } \\
\text { freedom }\end{array}$ & $\begin{array}{l}\text { Sum of } \\
\text { square }\end{array}$ & $\begin{array}{l}\text { Mean } \\
\text { square }\end{array}$ & $\begin{array}{l}\text { F } \\
\text { statistic }\end{array}$ & P-value & Predictor & Coefficient & $\begin{array}{l}\text { Standard } \\
\text { deviation }\end{array}$ & $\begin{array}{l}\text { T } \\
\text { statistic }\end{array}$ & P-value \\
\hline \multicolumn{11}{|c|}{ Simple linear regression } \\
\hline Regression & 1 & 1672.471 & 1672.471 & 18.72 & 0.003 & Constant & 57.24 & 34.87 & 4.68 & 0.002 \\
\hline Residual error & 8 & 714.633 & 89.329 & & & Ln (average temp.) & -26.72 & 6.17 & -4.32 & 0.003 \\
\hline Total & 9 & 2387.104 & & & & & \multicolumn{4}{|c|}{ Standard deviation $=8.45 \mathrm{R}^{2}=84 \%$} \\
\hline \multicolumn{11}{|c|}{ Multiple linear regression } \\
\hline Regression & 2 & 2131.710 & 1065.855 & 29.21 & 0.000 & Constant & 68.04 & 24.49 & 5.47 & 0.041 \\
\hline Residual error & 7 & 255.394 & 36.485 & & & Ln (minimum temp.) & -39.44 & 11.12 & -3.54 & 0.219 \\
\hline \multirow[t]{2}{*}{ Total } & 9 & 2387.104 & & & & Ln (average temp.) & -9.84 & 6.18 & -1.59 & 0.155 \\
\hline & & & & & & & \multicolumn{4}{|c|}{ Standard deviation $=6.04 ; \mathrm{R}^{2}=89.3 \%$} \\
\hline
\end{tabular}

Table 10. Analysis of variance output for simple and multiple linear regressions of natural logarithm of stem rust severity on the average temperature and the minimum temperature separately or together using the variety Kubsa at Kulumsa.

\begin{tabular}{|c|c|c|c|c|c|c|c|c|c|c|}
\hline Source & $\begin{array}{l}\text { Degree of } \\
\text { freedom }\end{array}$ & $\begin{array}{l}\text { Sum of } \\
\text { square }\end{array}$ & Mean square & F statistic & P-value & Predictor & Coefficient & $\begin{array}{l}\text { Standard } \\
\text { deviation }\end{array}$ & T statistic & P-value \\
\hline \multicolumn{11}{|c|}{ Simple linear regression } \\
\hline Regression & 1 & 1383.929 & 1383.929 & \multirow[t]{3}{*}{53.21} & \multirow[t]{3}{*}{0.000} & Constant & 30.35 & 38.46 & 7.94 & 0.000 \\
\hline Residual error & 8 & 208.071 & 26.009 & & & Ln (average temp.) & -17.85 & 2.44 & -7.29 & 0.000 \\
\hline Total & 9 & 1592.000 & & & & & \multicolumn{4}{|c|}{ Standard deviation $=5.09 ; \mathrm{R}^{2}=86.9 \%$} \\
\hline \multicolumn{11}{|c|}{ Multiple linear regression } \\
\hline Regression & 2 & 1425.011 & 712.505 & \multirow[t]{3}{*}{29.86} & \multirow[t]{3}{*}{0.000} & Constant & 91.70 & 88.54 & 2.25 & 0.059 \\
\hline \multirow[t]{2}{*}{ Total } & 9 & 1592.000 & & & & Ln (average temp.) & -8.12 & 7.78 & -1.04 & 0.331 \\
\hline & & & & & & & \multicolumn{4}{|c|}{ Standard deviation $=4.88 ; \mathrm{R}^{2}=89.5 \%$} \\
\hline
\end{tabular}

\section{Conclusions}

Results of the current study showed that stem rust development on the four bread wheat cultivars varied from year to year and from place to place. Rainfall increased the susceptibility of bread wheat cultivars to stem rust over the last 10 years at both locations. Results of this study suggest that the total seasonal rainfall played a significant positive effect on stem rust development, whereas seasonal mean minimum temperature and seasonal average relative humidity had negative impact on stem rust epidemic development. This finding suggests that the use of early maturing cultivar, resistant cultivar and early sowing date is crucial to manage stem rust epidemics development during the period of early onset rainfall, unless fungicide could be used on a susceptible cultivar at the appropriate time based on appropriate weather analysis. Changing disease scenarios due to climate variability has highlighted, thus the need for future studies on such models which can predict the severity of important pathogens of major crops in real-field conditions.

\section{Acknowledgements}

The authors are grateful thank Eastern Africa Agricultural Productivity Project (EAAPP) for the financial support and Oromia Agricultural Research Institute and Sinana Agricultural Research Center for provision of facilities, implementation of the research.

\section{Appendix}

Table A1. Reactions of four bread wheat cultivars to stem rust under field conditions at Sinana and Kulumsa during $2004-2013$.

\begin{tabular}{|c|c|c|c|c|c|c|c|c|}
\hline \multirow{3}{*}{ Year } & \multirow{2}{*}{\multicolumn{2}{|c|}{$\begin{array}{l}\text { Field reaction } \\
\text { Madawalabu }\end{array}$}} & \multicolumn{2}{|l|}{ Field reaction } & \multicolumn{2}{|l|}{ Field reaction } & \multicolumn{2}{|l|}{ Field reaction } \\
\hline & & & Sofumer & & Tusie & & Kubsa & \\
\hline & Terminal severity & CI value & Terminal severity & CI value & Terminal severity & CI value & Terminal severity & CI value \\
\hline \multicolumn{9}{|l|}{ A) Sinana } \\
\hline 2004 & TR & 0.2 & TMR/MR & 0.4 & $20 \mathrm{~S}$ & 20 & $30 \mathrm{~S}$ & 30 \\
\hline 2005 & TR & 0.2 & TMR/MS & 0.6 & $40 \mathrm{~S}$ & 40 & $35 \mathrm{~S}$ & 35 \\
\hline
\end{tabular}




\begin{tabular}{|c|c|c|c|c|c|c|c|c|}
\hline \multirow{3}{*}{ Year } & \multirow{2}{*}{\multicolumn{2}{|c|}{$\begin{array}{l}\text { Field reaction } \\
\text { Madawalabu } \\
\end{array}$}} & \multicolumn{2}{|l|}{ Field reaction } & \multicolumn{2}{|l|}{ Field reaction } & \multicolumn{2}{|l|}{ Field reaction } \\
\hline & & & Sofumer & & Tusie & & Kubsa & \\
\hline & Terminal severity & CI value & Terminal severity & CI value & Terminal severity & CI value & Terminal severity & CI value \\
\hline 2006 & $5 \mathrm{MS}$ & 4 & $10 \mathrm{~S}$ & 10 & $20 \mathrm{~S}$ & 20 & $10 \mathrm{~S}$ & 10 \\
\hline 2007 & $15 \mathrm{MR}$ & 6 & $30 \mathrm{~S}$ & 30 & $40 \mathrm{~S}$ & 40 & $40 \mathrm{~S}$ & 40 \\
\hline 2008 & $5 \mathrm{~S}$ & 5 & $20 \mathrm{~S}$ & 20 & $30 \mathrm{~S}$ & 30 & $40 \mathrm{~S}$ & 40 \\
\hline 2009 & TMR/MS & 0.6 & TS & 1 & TMS & 0.8 & TMR/MS & 0.6 \\
\hline 2010 & TMS & 0.8 & TMS & 0.8 & $10 \mathrm{~S}$ & 10 & $10 \mathrm{~S}$ & 10 \\
\hline 2011 & $5 \mathrm{~S}$ & 5 & $10 \mathrm{~S}$ & 10 & $10 \mathrm{~S}$ & 10 & $5 \mathrm{~S}$ & 5 \\
\hline 2012 & $5 \mathrm{MS}$ & 4 & $15 \mathrm{~S}$ & 15 & $15 \mathrm{~S}$ & 15 & $10 \mathrm{~S}$ & 10 \\
\hline 2013 & $10 \mathrm{~S}$ & 10 & $30 \mathrm{~S}$ & 30 & $35 \mathrm{~S}$ & 35 & $30 \mathrm{~S}$ & 30 \\
\hline \multicolumn{9}{|c|}{ B) Kulumsa } \\
\hline 2004 & TS & 1 & $10 \mathrm{~S}$ & 10 & $25 \mathrm{~S}$ & 25 & $30 \mathrm{~S}$ & 30 \\
\hline 2005 & $5 \mathrm{MS}$ & 4 & $15 \mathrm{~S}$ & 15 & $20 \mathrm{~S}$ & 20 & $25 \mathrm{~S}$ & 25 \\
\hline 2006 & $5 \mathrm{~S}$ & 5 & $20 \mathrm{~S}$ & 20 & $30 \mathrm{~S}$ & 30 & $35 \mathrm{~S}$ & 35 \\
\hline 2007 & $5 \mathrm{~S}$ & 5 & $15 \mathrm{~S}$ & 15 & $20 \mathrm{~S}$ & 20 & $40 \mathrm{~S}$ & 40 \\
\hline 2008 & $15 \mathrm{MR}$ & 6 & $15 \mathrm{~S}$ & 15 & $20 \mathrm{~S}$ & 20 & $25 \mathrm{~S}$ & 25 \\
\hline 2009 & $15 \mathrm{~S}$ & 15 & $40 \mathrm{~S}$ & 40 & $40 \mathrm{~S}$ & 40 & $40 \mathrm{~S}$ & 40 \\
\hline 2010 & $10 \mathrm{~S}$ & 10 & $20 \mathrm{~S}$ & 20 & $25 \mathrm{~S}$ & 25 & $30 \mathrm{~S}$ & 30 \\
\hline 2011 & $10 \mathrm{~S}$ & 10 & $20 \mathrm{~S}$ & 20 & $15 \mathrm{~S}$ & 15 & $30 \mathrm{~S}$ & 30 \\
\hline 2012 & $5 \mathrm{~S}$ & 5 & $10 \mathrm{~S}$ & 10 & $10 \mathrm{~S}$ & 10 & $5 \mathrm{~S}$ & 5 \\
\hline 2013 & $10 \mathrm{~S}$ & 10 & $15 \mathrm{~S}$ & 15 & $15 \mathrm{~S}$ & 15 & $5 \mathrm{~S}$ & 5 \\
\hline
\end{tabular}

${ }^{*} \mathrm{CI}=$ Coefficient of infection, $\mathrm{T}=$ trace, $\mathrm{R}=$ resistant, $\mathrm{MR}=$ moderately resistant, $\mathrm{MS}=$ moderately susceptible, $\mathrm{S}=$ susceptible.

Source: Sinana and Kulumsa Agricultural Research centers.

Table A2. Correlation coefficients (r) among independent weather variables at Sinana.

\begin{tabular}{lllll}
\hline Parameters & Minimum temperature & Maximum temperature & Average temperature & Total rainfall \\
\hline Minimum temperature & 1 & & & \\
Maximum temperature & -0.02 & 1 & 1 & \\
Average temperature & $0.77^{* *}$ & 0.60 & -0.11 & 1 \\
Total rainfall & -0.09 & -0.19 & & \\
\hline
\end{tabular}

** Correlation is significant at $P \leq 0.01$.

Table A3. Correlation coefficients (r) among independent weather variables at Kulumsa.

\begin{tabular}{llllll}
\hline Parameters & Minimum temperature & Maximum temperature & Average temperature & Total rainfall & Relative humidity \\
\hline Minimum temperature & 1 & & & & \\
Maximum temperature & 0.15 & 1 & & & \\
Average temperature & $0.95^{* *}$ & 0.43 & 0.21 & 1 & \\
Total rainfall & 0.25 & -0.24 & -0.18 & -0.32 & 1 \\
Relative humidity & -0.02 & -0.46 & & \\
\hline
\end{tabular}

** Correlation is significant at $P \leq 0.01$.

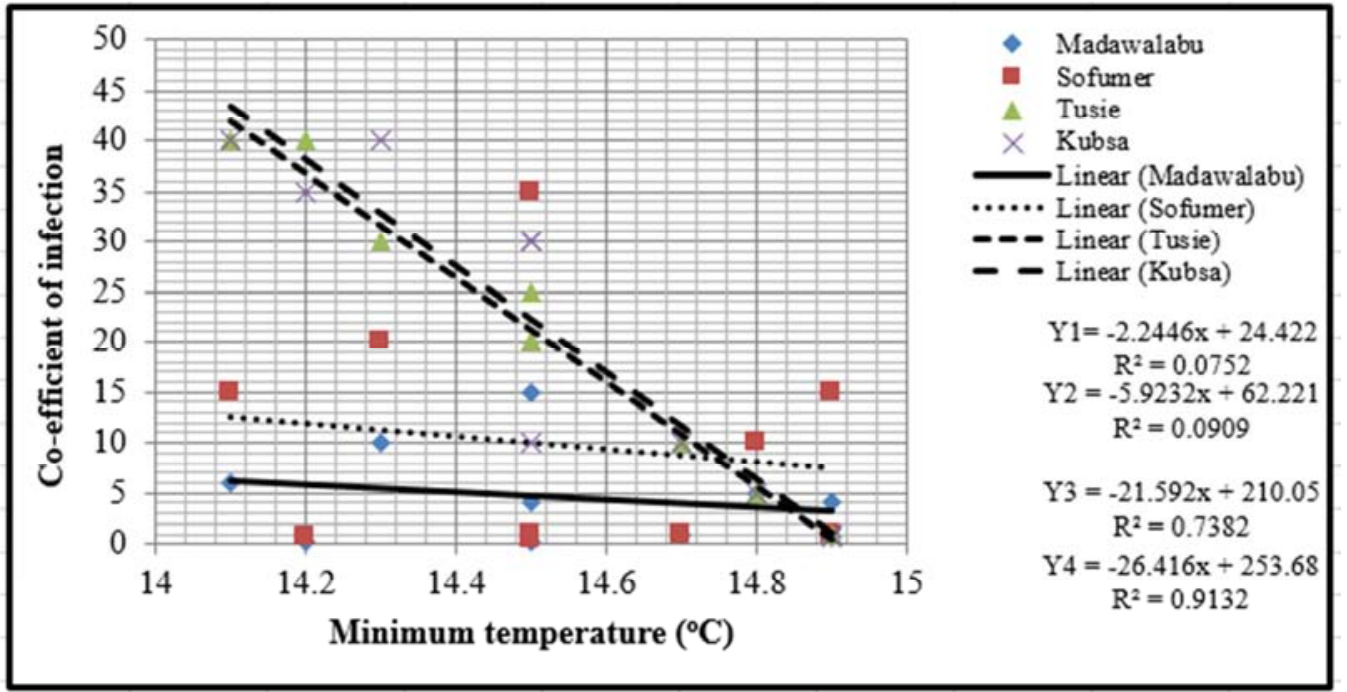

Figure A1. Effect of minimum temperature on co-efficient infection of stem rust on Madawalabu (Y1), Sofumer (Y2), Tusie (Y3) and Kubsa (Y4) at Sinana. 


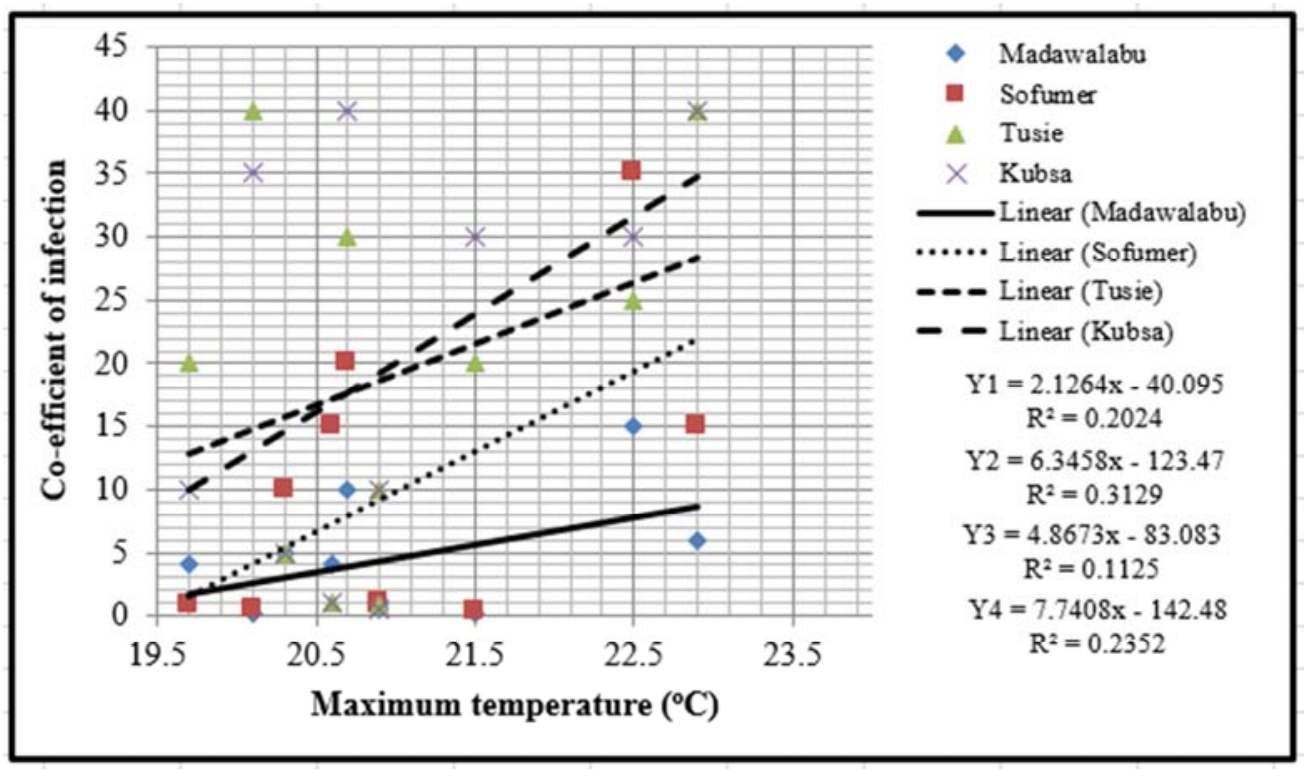

Figure A2. Effect of maximum temperature on co-efficient infection of stem rust on Madawalabu (Y1), Sofumer (Y2), Tusie (Y3) and Kubsa (Y4) at Sinana.

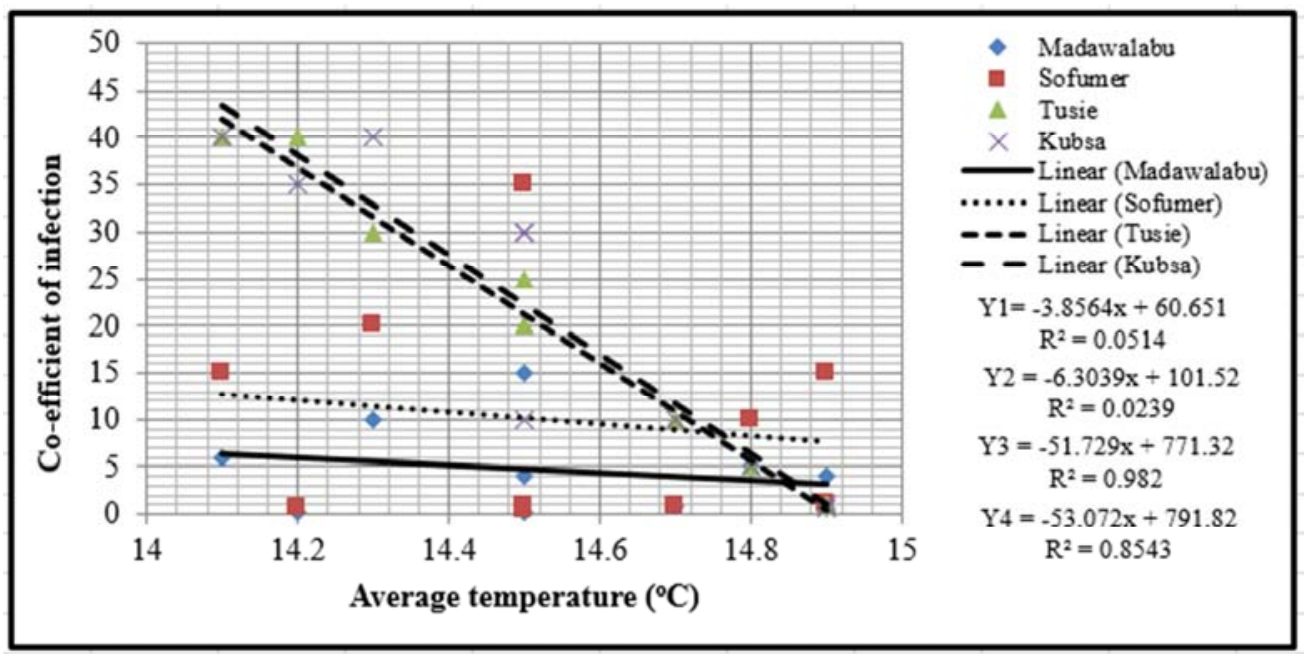

Figure A3. Effect of average temperature on co-efficient infection of stem rust on Madawalabu (Y1), Sofumer (Y2), Tusie (Y3) and Kubsa (Y4) at Sinana.

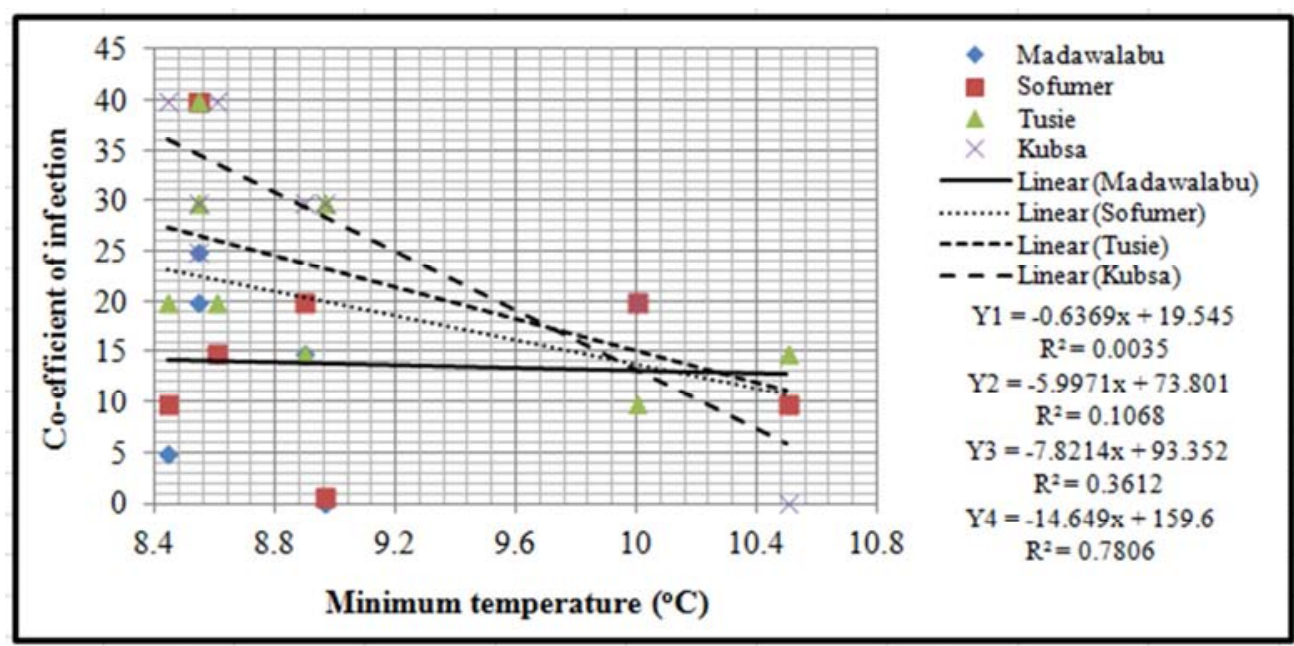

Figure A4. Effect of minimum temperature on co-efficient infection of stem rust on Madawalabu (Y1), Sofumer (Y2), Tusie (Y3) and Kubsa (Y4) at Kulumsa. 


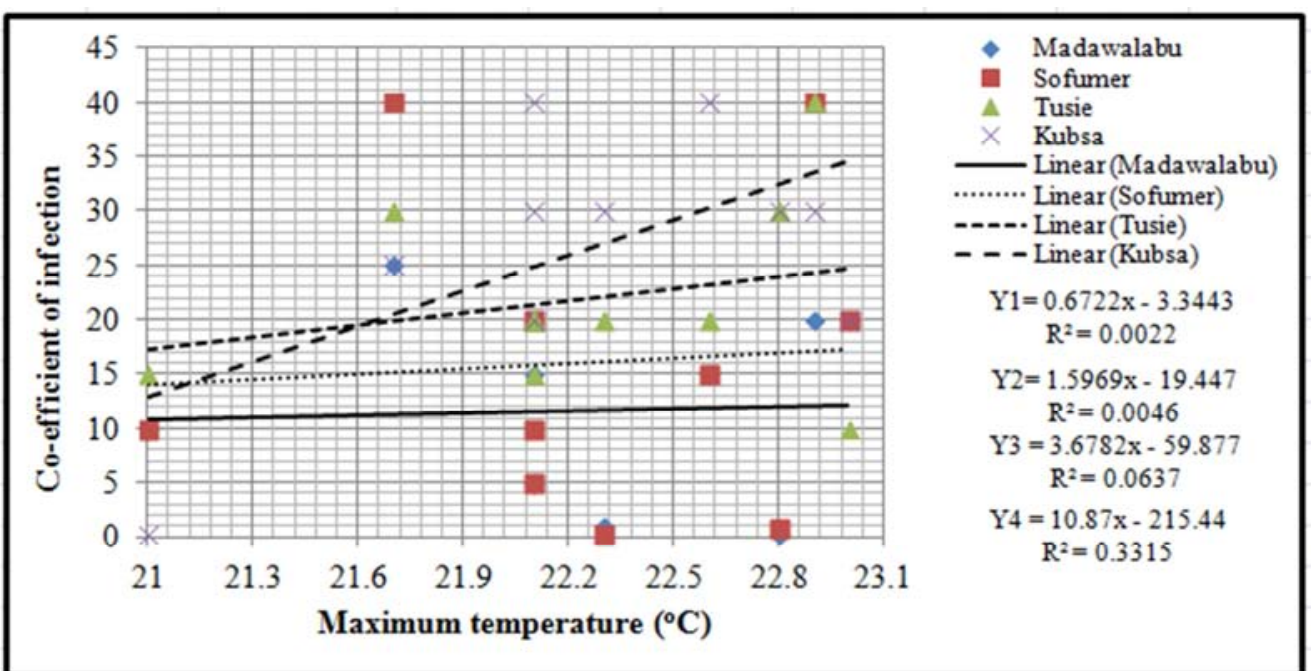

Figure A5. Effect of maximum temperature on co-efficient infection of stem rust on Madawalabu (Y1), Sofumer (Y2), Tusie (Y3) and Kubsa (Y4) at Kulumsa.

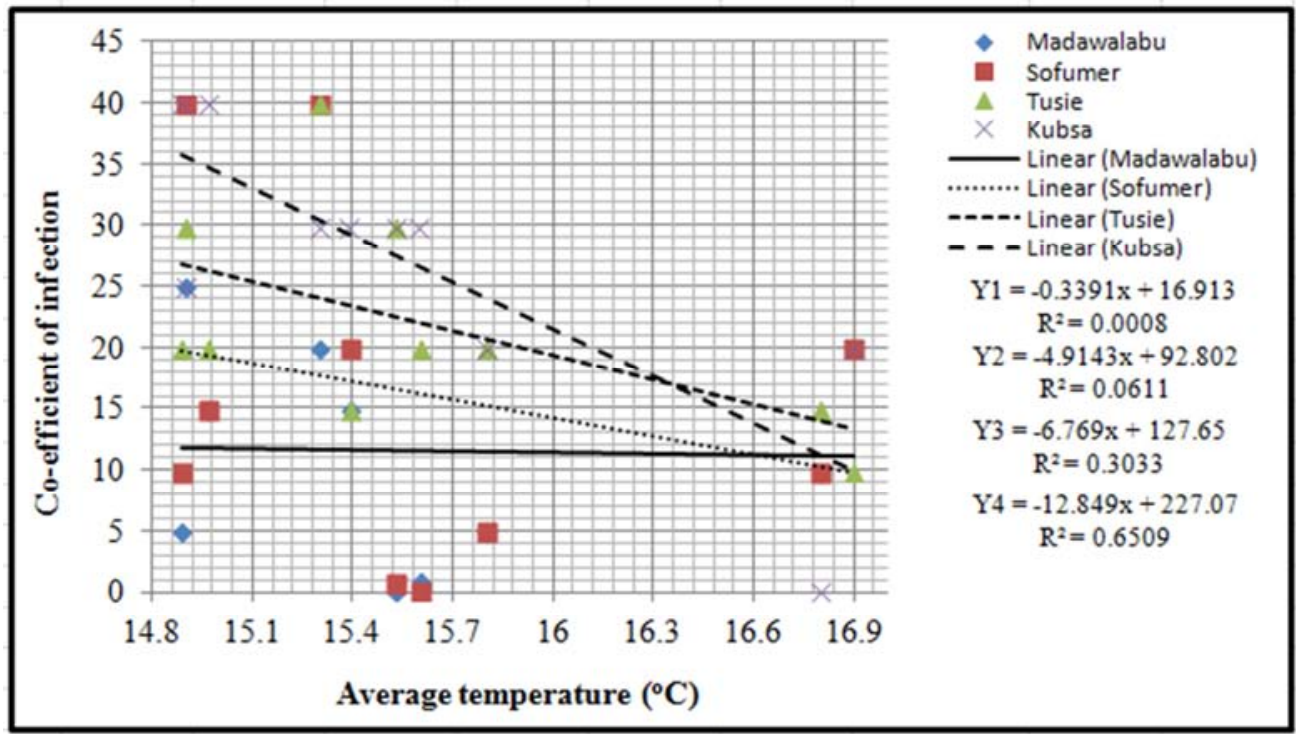

Figure A6. Effect of average temperature on co-efficient infection of stem rust on Madawalabu (Y1), Sofumer (Y2), Tusie (Y3) and Kubsa (Y4) at Kulumsa.

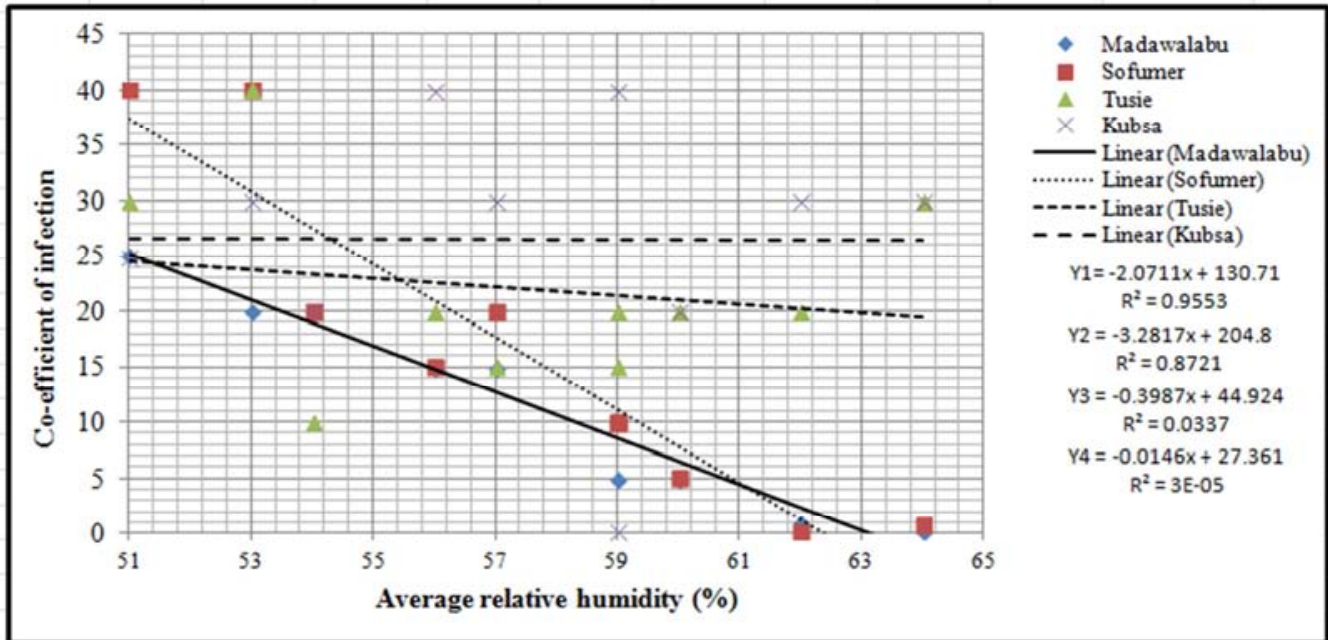

Figure A7. Effect of average relative humidity on co-efficient infection of stem rust on Madawalabu (Y1), Sofumer (Y2), Tusie (Y3) and Kubsa (Y4) at Kulumsa. 


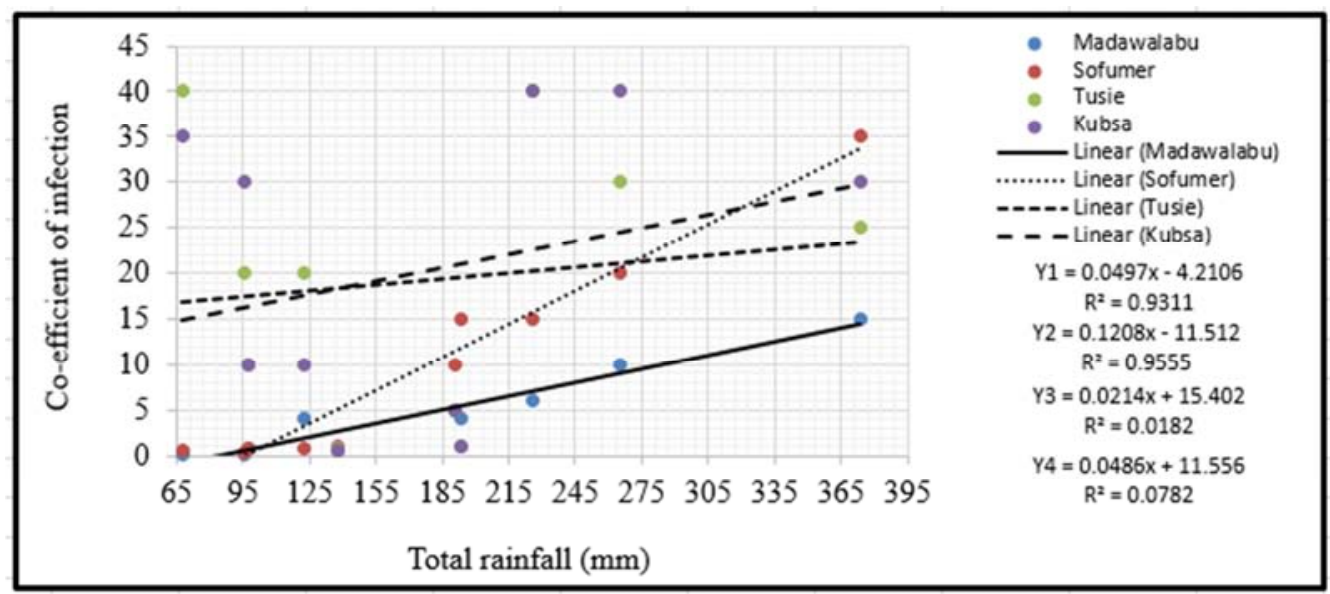

Figure A8. Effect of seasonal rainfall on co-efficient infection of stem rust on Madawalabu (Y1), Sofumer (Y2), Tusie (Y3) and Kubsa (Y4) at Sinana.

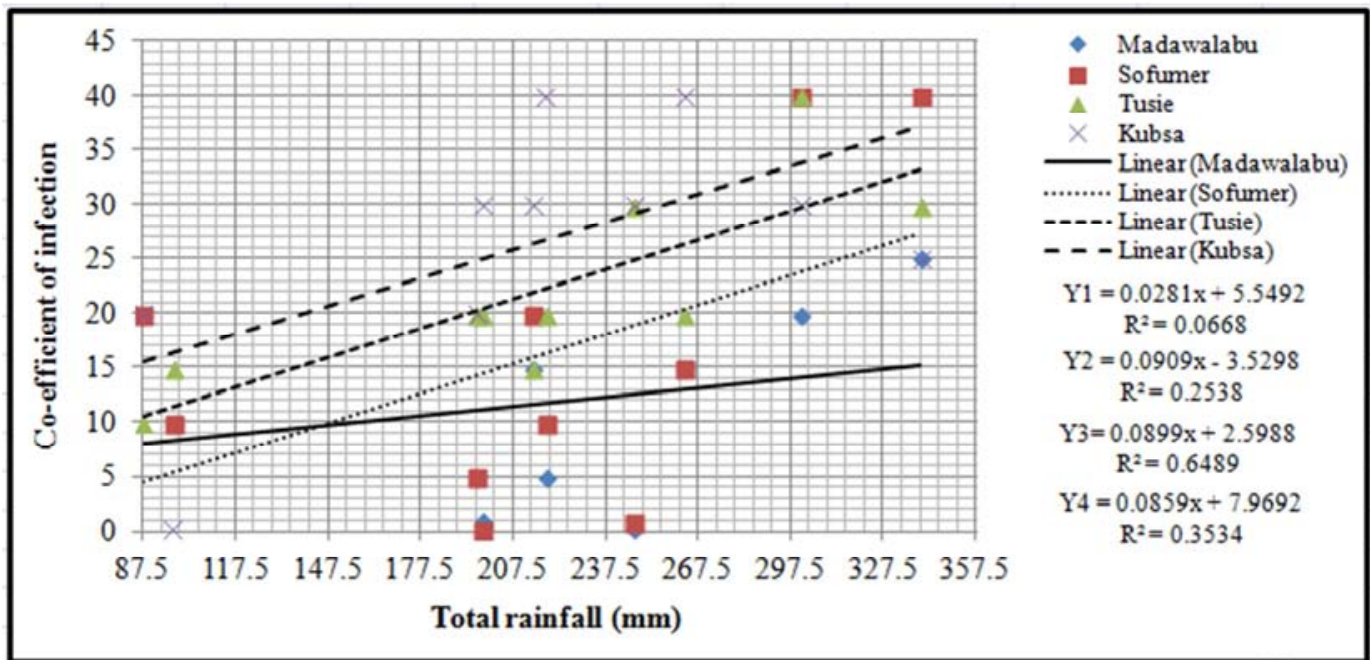

Figure A9. Effect of seasonal rainfall on co-efficient infection of stem rust on Madawalabu (Y1), Sofumer (Y2), Tusie (Y3) and Kubsa (Y4) at Kulumsa.

\section{References}

[1] Bekele Hundie, Verkuiji, H., Mawangi, W. and Tanner, D. G. 2000. Adaptation of improved wheat technologies in Adaba and Dodola Woredas of the Bale highlands of Ethiopia. CIMMYT/EARO, Addis Ababa, Ethiopia.

[2] Bekele Hundie. 2003. Short report on yellow rust and stem rust. pp. 67-78. In: Bedada Girma (ed.). Proceedings of the Agronomy Workshop Organized by Bale Agricultural Development Enterprise. Nazereth, Ethiopia.

[3] Bolton, M. D., Kolmer, J. A., and Garvin, D. F. 2008. Pathogen profile: Wheat leaf rust caused by Puccinia triticina. Molecular Plant Pathology. 9 (5): 563-575.

[4] Campbell, C. L., and Madden, L. V. 1990. Introduction to Plant Disease Epidemiology. New York, USA: John Wiley.

[5] CIMMYT (International Center for Maize and Wheat Improvement). 2005. Sounding the alarm on global stem rust: An assessment of race Ug99 in Kenya and Ethiopia and the potential for impact in neighboring regions and beyond. Expert Panel Report. International Center for Maize and Wheat Improvement (CIMMYT), Mexico. 26 p.
[6] Couture, L. and Sutton, J. C. 1978. Relation of weather variables and host factors to incidence of airborne spores of Bipolaris Sorokiniana. Canadian Journal of Botany 56: 21622170.

[7] CSA (Central Statistical Agency). 2010/11. Large and Medium Scale Commercial Farms Sample Survey. Statistical Report on Area and Production of Crops, and Farm Management Practices. Statistical Bulletin 505. Addis Ababa, Ethiopia.

[8] CSA (Central Statistical Agency). 2015. Agricultural sample survey, 2014/2015. Report on Area and Production of Major Crops. CSA May 2015. Available at: www.csa.gov.et.

[9] Daamen, R. A., Stubbs, R. W. and Stol, W. 1992. Surveys of cereal diseases and pests in the Netherlands. Occurrence of powdery mildew and rusts in winter wheat. Netherland Journal of Plant Pathology. 98: 301-312.

[10] Dagnachew Yirgu. 1967. Plant Diseases of Economic Importance in Ethiopia. Exp. Station Bull. No. 50. College of Agriculture, Debre-Ziet, Ethiopia.

[11] Dreisigacker, S. 2004. Genetic diversity in elite lines and land races of CIMMYT spring bread wheat and hybrid performance of crosses among elite germplasm. Published doctoral dissertation. Faculty of Agricultural University of Hohenheim 
[12] Eshetu Bekele. 1986. A Review of Research on Diseases of Barley, Tef and Wheat in Ethiopia pp 79-148. In: Tsedeke Abate (eds). A Review of Crop Protection Research in Ethiopia. Proceeding of the First Ethiopian Crop Protection Symposium. 4-7 February, 1985. Addis Ababa, Ethiopia.

[13] Eversmeyer, M. G, and Kramer, C. L. 1995. Survival of Puccinia recondita and P. graminis urediniospores exposed to temperatures from subfreezing to $35^{\circ} \mathrm{C}$. Phytopathology, 85: 161-164.

[14] Fox, S. L. and D. E. Harder. 1995. Resistance to stem rust in selected barley lines and the inheritance of resistance to pathotype QCC. Canadian Journal of Plant Science. 75: 781788. 6.

[15] Hailu, G. M. 1991. Wheat production and research in Ethiopia pp: 1-15. In: Hailu G, Tanner, DG. and Mengistu H (eds). Wheat research in Ethiopia: A historical perspective. Addis Ababa, IAR/CIMMYT.

[16] Jin, Y., Steffenson, B. J. and Miller, J. D. 1994. Inheritance of Resistance to Pathotypes QCC and MCC of Puccinia graminis f.sp. tritici. In: barley lines Q21861 and Temperature Effect on the Expression of Resistance. Phytopathology 84: 452-455.

[17] Khan, M. A., Yaqub, M. and Nasir, M. A. 1998. Slow rusting response of wheat genotypes against Puccinia recondite f.sp. tritici in relation to environmental conditions. Pakistan Journal of Phytopathology. 10: 78-85.

[18] Kurt, S. 2002. Screening of wheat cultivars for resistance to stripe rust and leaf blotch in Turkey Crop Protection 21:495500 .

[19] Loegering, W. Q. 1959. Methods of recording cereal rust data U. S. D. A international spring wheat rust nursery.

[20] Minitab for windows. 1998. Version 12.21, Minitab Inc.

[21] Montgomery, D. C. and Peck, E. A. 1982. Introduction to linear regression analysis. John Wiley and Sons, New York. $504 \mathrm{pp}$.
[22] Myers, R. H. 1990. Classical and Modern Regression with Application. 2nd ed. PWS-KENT Puhl. Co., Boston, USA.

[23] Peterson, D. P. 2001. Stem Rust of Wheat from Ancient Enemy to the Modern Foe. The American Phytopathological Society. APS Press. St. Paul, Minnesota.

[24] Peterson, R. F., Campbell, A. B. and Hannah, A. E. 1948. A diagrammatic scale for estimating rust intensity of leaves and stem of cereals. Canadian Journal of Research Section C. 26: 496-500.

[25] SARC (Sinana Agricultural Research Center). 2004. Sinana Agricultural Research Center Pathology Department Progress Reports for the Period 2002-2004. Sinana, Bale, Ethiopia.

[26] Serbassa Negera. 2003. Wheat stem (Puccinia graminis f.sp. tritici) intensity and pathogenic variability in Arsi and Bale Zones of Ethiopia. M.Sc. Thesis. The School of Graduate Studies of Alemaya University, Ethiopia.

[27] Shank, R. 1994. Wheat stem rust and drought effect on Bale agricultural production and future prespects. Summerized report. 17-19 February. UNDP emergency Unit in Ethiopia. Addis Ababa. 5p.

[28] Singh, R. P., Huerta-Espino, J. and Roelfs, A. P. 2002. The Wheat Rusts. pp. 554. In: B. C. Curtis, S. Rajaram, H. Gomez Macpherson (eds.). Bread Wheat Improvement and Production. Food and Agriculture Organization (FAO) of the United Nations. Rome, Italy.

[29] Singh, R. P., Hodson, D. P., Huerta-Espino, J., Jin, Y., Njau, P., Wanyera, R., Herrera Foessel, S. A. and Ward, R. W. 2008. Will stem rust destroy the world's wheat crop? Advances in Agronomy. 98: 271-309.

[30] Steel, R. G. D. and Torrie, J. H. 1986. Principles and Procedures of Statistics. $2^{\text {nd }} E d$. MacGraw Hill Book Inter. Co. New York. 